


\section{Los Centroamericanos en Estados Unidos}

José Arnoldo Sermeño Lima

RESUMEN. Considerando la importancia de la emigración centroamericana como fenómeno social y económico, el artículo hace una descripción cuantitativa de los movimientos de población de cada país de la región hacia los Estados Unidos (EUA), utilizando principalmente la información del último censo de población de este país, realizado en 2010. El estudio inicia enfatizando la importancia de los migrantes tipificados como latinos o hispanos en cada estado de la unión norteamericana, clasificando los estados según la presencia numérica de migrantes así como el crecimiento en número que ellos han tenido durante el último período intercensal. Se seleccionan indicadores socioeconómicos para comparar los entornos que rodean a los emigrantes de cada país centroamericano antes y después de efectuar el movimiento migratorio; es decir, las condiciones que les rodeaban primero en su respectivo país de origen y luego en los estados de EUA donde los emigrantes de cada uno de esos países son mayoritarios entre la emigración centroamericana, para derivar de esa información el cambio experimentado por ellos al trasladarse de uno a otro ambiente, o si regresan a su lugar de origen. Esta comparación se efectúa advirtiendo al lector las restricciones en disponibilidad de información, así como las diferencias conceptuales que pueden esconderse tras los indicadores y asimismo sobre las diferencias de calidad al obtener los indicadores en los diferentes países.

Palabras clave: migración, centroamericanos, condiciones de vida promedio, pobreza, concentración de Gini, poder adquisitivo, mortalidad materna y en menores de 5 años, esperanza de vida al nacer, remesas, deportados.

ABSTRACT. Considering the importance of the Central American emigration like a social and economic phenomenon, this article makes a quantitative description about the population movements of each country from this region to the United States, principally using the information of these migrants in the last population census of this country, made in 2010. The article begins emphasizing the importance of the migrants, established like Latins or Hispanics, on each state of USA, classifying the states for the numbers of the migrant's presence on each of them and also the growing number of migrants during the last intercensal period. Socioeconomic indicators are selected to compare the environment surrounding the migrants on each Centro American country before and after making the migrant movement, it means, the first conditions that surrounded them on their country and then when they move to the states of the USA, where emigrants of each Central American country are the majority among the Central American emigrants. These comparisons are made advising the reader not just about the restrictions of information, but also the conceptual differences that can hide behind the indicators and about the quality differences of getting the indicators in different countries.

Keywords: migration, central american, average Life's condition, poverty, Gini concentration, purchasing power, maternity mortality, under five ages mortality, life expectative at birth, remittance, deported.

\section{Introducción}

Es indudable la importancia que tiene en la economía centroamericana la población que ha emigrado en los últimos años, al jugar un papel relevante como emisores de remesas. Entre los años 2000 y 2010 todos los países de la región aumentaron los montos absolutos de las mismas, teniendo naturalmente mayor significado relativo en los países que menos recibieron al inicio de ese período. En el Cuadro No.1 se observa que su relación con el Pro- ducto Interno Bruto (PIB) en el año 2010 cobra especial importancia en El Salvador, Guatemala, Honduras y Nicaragua; incrementándose significativamente en ese período en todos los países, especialmente en aquellos que al inicio recibían menos.

Estas cifras no revelan el drama humano que está atrás de ellas, lo que apenas trasluce en el incremento de deportaciones experimentadas especialmente en los tres países del triángulo norte: El Salvador, Guatemala y Honduras (Gráfico No.1). 
Cuadro No. 1. 2000 y 2012: Remesas y POB para cada País Centroamericano

\begin{tabular}{|c|c|c|c|c|c|c|c|c|c|}
\hline \multirow[b]{2}{*}{ País } & \multicolumn{3}{|c|}{ Remesas (\$EUA Millones) } & \multicolumn{3}{|c|}{ PIB (\$EUA Millones) (b) } & \multicolumn{3}{|c|}{ Remesas/PIB (\%) } \\
\hline & 2000 & 2010 (a) & $\Delta 2000-10(\%)$ & 2000 & 2010 & $\Delta 2000-10(\%)$ & 2000 & 2010 (a) & $\Delta 2000-10(\%)$ \\
\hline Belice & 27.8 & 80.0 & 187.8 & 832.0 & $1,383.0$ & 66.2 & 3.3 & 5.8 & 73.1 \\
\hline Costa Rica & 12.3 & 264.8 & $2,052.8$ & $15,947.0$ & $34,346.0$ & 115.4 & 0.1 & 0.8 & 899.6 \\
\hline El Salvador & $1,750.7$ & $3,465.0$ & 97.9 & $13,134.0$ & $21,512.0$ & 63.8 & 13.3 & 16.1 & 20.8 \\
\hline Guatemala & 563.4 & $3,912.3$ & 594.4 & $17,196.0$ & $40,624.0$ & 136.2 & 3.3 & 9.6 & 193.9 \\
\hline Honduras & 440.6 & $2,475.7$ & 461.9 & $7,187.0$ & $15,361.0$ & 113.7 & 6.1 & 16.1 & 162.9 \\
\hline Nicaragua & 320.0 & 768.4 & 140.1 & $3,938.0$ & $6,433.0$ & 63.4 & 8.1 & 11.9 & 47.0 \\
\hline Panamá & & 168.0 & & $11,621.0$ & $26,473.0$ & 127.8 & - & 0.6 & - \\
\hline
\end{tabular}

(a) 2009 para Remesas

(b) PIB a precios corrientes

Fuente: Estado de la Región, 2010; p. 117 y 533

Gráfico No. 1. 2001-2010: Deportados Centroamericanos desde Estados Unidos, por País de Origen

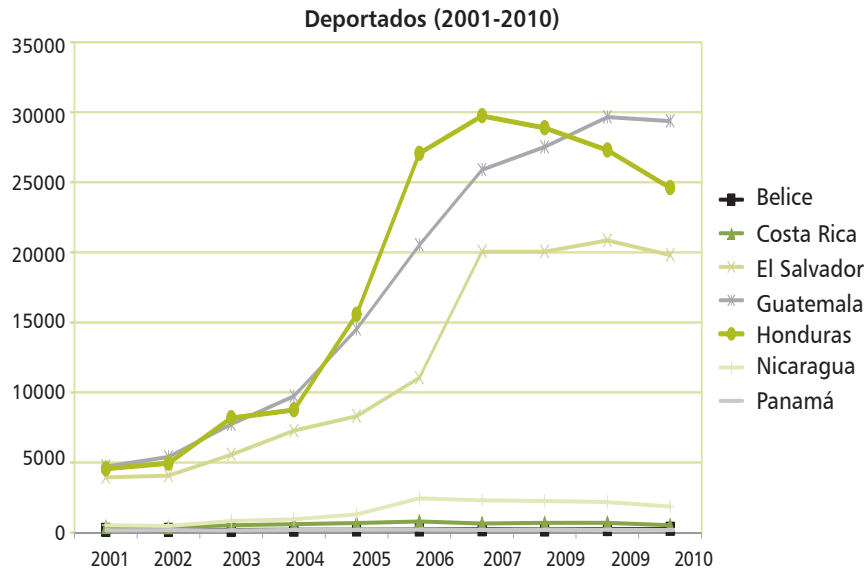

Fuente: U. S. Department of Homeland Security (2010), Yearbook of Immigration Statistics, http://1.usa.gov/rk4SOy

Este artículo no pretende estudiar las tragedias humanas implícitas en esas cifras, sino aproximarse a ello por medio de dos grandes temas: en primer lugar determinar cuántos son los centroamericanos que residen en cada estado de la unión norteamericana; y luego describir cómo cambia el entorno en que ellos viven antes y después de migrar, al comparar indicadores primero en su país de origen y luego al emigrar hacia los Estados Unidos, lo que obviamente se revierte para aquellos que son deportados.

\section{Metodología}

El artículo es de alcance descriptivo, analiza cuantitativamente la inmigración de centroamericanos registrada en el último Censo de Población de los Estados Unidos de América (EUA) del año 2010, que se clasifica como "hispana" o "latina", para luego focalizarse en la de origen centroamericano (CA). También usa encuestas realizadas por el Pew Hispanic Center en el año 2008 y 2009 aplicadas a la población hispana residente.

Se determina cuáles nacionalidades Centroamericanas impactan más numéricamente en cada estado de la unión norteamericana, haciendo énfasis en cuáles estados tienen una concentración alta, media, baja o muy baja de emigrantes $^{1}$ de cada país de Centro América. También se analiza cómo cada nacionalidad Centroamericana se distribuye entre cada estado de la unión. La distribución de estas poblaciones se realiza mediante la utilización de mapas, en los que se marca su concentración en los diferentes estados.

Finalmente se presentan algunos indicadores socioeconómicos de los países CA para compararlos con los de aquellos estados de EUA donde más se concentran los emigrados de CA, y así contrastar el entorno que han dejado atrás en su país de origen con el que encuentran en el estado de destino.

1. En lo referente a la redacción, en este documento se ha adoptado la opinión de expertos gramaticales que señalan que mencionar ambos géneros es correcto sólo cuando el masculino y femenino son palabras diferentes (como mujeres y hombres, damas y caballeros, etc.). De lo contrario, debe comprenderse que el plural en masculino implica a ambos sexos. Asimismo, el participio activo de un verbo se refiere a ambos sexos, sin requerir precisión individual para cada uno: por ejemplo, el participio activo de "migrar" es "migrante", el de "emigrar" es "emigrante", etc. 


\section{Los Latinos en los Estados Unidos}

De la información obtenida por los censos de población de los EUA puede analizarse la distribución de la población que en el mismo califican como de origen latino o "hispanos" por medio de dos tipos de indicadores: a) Porcentaje de la población de origen latino o hispana residente en cada estado en 2010 y b) Clasificación según crecimiento de la población de origen latina o hispana registrada en los censos efectuados en los años 2000 y 2010. Se agrega además el análisis al combinar ambos indicadores.

En la sección "a” del Cuadro No.2 se ha clasificado a los estados según el porcentaje de latinos en su población en 2010. ${ }^{2}$ Tanto ahí como en el Mapa No.1 puede observarse que los estados donde la presencia latina era porcentualmente más significativa se encuentran en 5 estados del sur-occidente y sur-centro del país: California, Nevada, Arizona, Nuevo México y Texas. También puede constatarse que los estados con presencia "Media" de hispanos son 12, ubicados tanto en las zonas noroccidental y central, cercanas a las anteriores: Washington, Oregón, Idaho, Utah, Colorado y Kansas; como también en algunos de la región nororiental (Nueva York, Connecticut, Rhode Island y Nueva Jersey), así como en Illinois al centro y Florida al suroriente. En el caso de los restantes 33 estados y en el Distrito de Columbia la presencia latina en 2010 constituyó menos de 10\% de su respectiva población:

\section{Cuadro No. 2. Clasificación de los Estados: a) Según Población de Ori- gen Latino o "Hispánico" en 2010 (\%) y b) Según el Crecimiento de Ésta entre 2000 y 2010}

\begin{tabular}{|c|c|c|c|c|c|}
\hline \multicolumn{3}{|c|}{$\begin{array}{l}\text { a) Clasificación según Porcentaje } \\
\text { de Población de Origen Latino, } 2010\end{array}$} & \multicolumn{3}{|c|}{$\begin{array}{l}\text { b) Clasificación según Crecimiento de Población } \\
\text { Latina entre } 2000-2010(\%)\end{array}$} \\
\hline Bajo & Medio & Alto & Bajo & Medio & Alto \\
\hline Alabama & Colorado & Arizona & & D.C. & Alabama \\
\hline Alaska & Connecticut & California & & New México & Alaska \\
\hline Arkansas & Florida & Nevada & & New York & Arizona \\
\hline D.C. & Idaho & New México & & & Arkansas \\
\hline Delaware & Illinois & Texas & & & California \\
\hline Georgia & Kansas & & & & Colorado \\
\hline Hawaii & New Jersey & & & & Connecticut \\
\hline Indiana & New York & & & & Delaware \\
\hline lowa & Oregon & & & & Florida \\
\hline Kentucky & Rhode Island & & & & Georgia \\
\hline Louissiana & Utah & & & & Hawaii \\
\hline Maine & Washington & & & & Idaho \\
\hline Maryland & & & & & Illinois \\
\hline Massachusetts & & & & & Indiana \\
\hline Michigan & & & & & lowa \\
\hline Minnesota & & & & & Kansas \\
\hline Mississippi & & & & & Kentucky \\
\hline Missouri & & & & & Louissiana \\
\hline Montana & & & & & Maine \\
\hline Nebraska & & & & & Maryland \\
\hline New Hampshire & & & & & Massachusetts \\
\hline North Carolina & & & & & Michigan \\
\hline North Dakota & & & & & Minnesota \\
\hline Ohio & & & & & Mississippi \\
\hline Oklahoma & & & & & Missouri \\
\hline Pennsylvania & & & & & Montana \\
\hline South Carolina & & & & & Nebraska \\
\hline South Dakota & & & & & Nevada \\
\hline Tennessee & & & & & New Hampshire \\
\hline Vermont & & & & & New Jersey \\
\hline Virginia & & & & & North Carolina \\
\hline West Virginia & & & & & North Dakota \\
\hline Wisconsin & & & & & Ohio \\
\hline \multirow[t]{15}{*}{ Wyoming } & & & & & Oklahoma \\
\hline & & & & & Oregón \\
\hline & & & & & Pennsylvania \\
\hline & & & & & Rhode Island \\
\hline & & & & & South Carolina \\
\hline & & & & & South Dakota \\
\hline & & & & & Tennessee \\
\hline & & & & & Texas \\
\hline & & & & & Utah \\
\hline & & & & & Vermont \\
\hline & & & & & Virginia \\
\hline & & Criterio & Valor & & Washington \\
\hline & & Bajo & $<10 \%$ & & West Virginia \\
\hline & & Medio & $10-24.99 \%$ & & Wisconsin \\
\hline & & Alto & 25 \% ó más & & Wyoming \\
\hline
\end{tabular}

Fuente: Cuadro A del Anexo.

2. Se consideró como de presencia "Baja" de latinos los estados donde la población de dicho origen es inferior a $10 \%$, "Media" aquellos donde es entre $10 \%$ y $24.9 \%$, y "Alta" si es de $25 \%$ ó más. 
Mapa No. 1. 2010: Estados Según Presencia de Población Latina (\%)

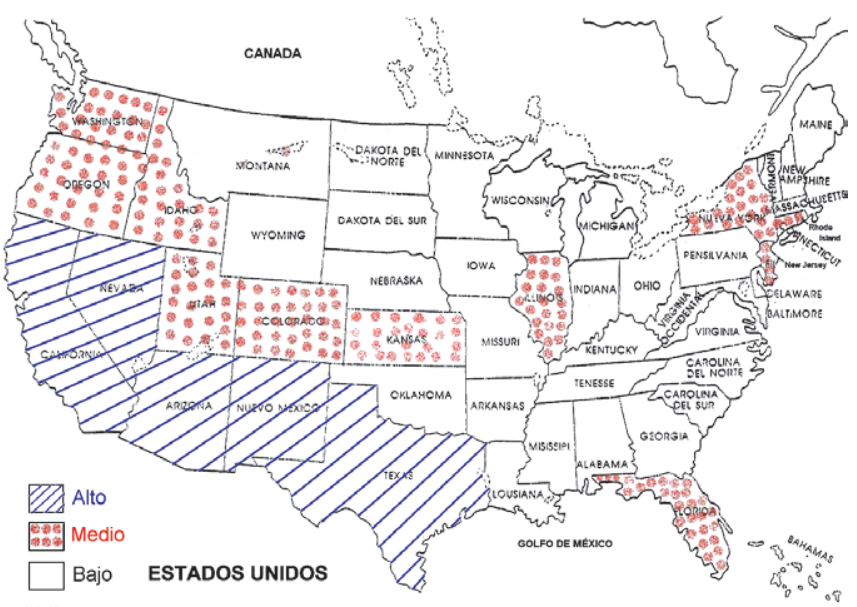

Fuente: Cuadro 2

A pesar que la presencia latina fue "Baja" en 34 divisiones territoriales "Alta" sólo en 5 y "Media" en 12-, debe agregarse que entre los años 2000 y 2010 el porcentaje de población latina se incrementó en todas las divisiones geográficas analizadas: 48 estados tuvieron un crecimiento superior a 25\%, y sólo dos (Nuevo México y Nueva York) así como el Distrito de Columbia tuvieron un incremento intermedio, como puede constatarse en el Mapa No.2 y en la parte "b” del Cuadro No.2:

\section{Mapa No. 2. Estados según Crecimiento de la Población Latina entre 2000 y 2010 (\%)}

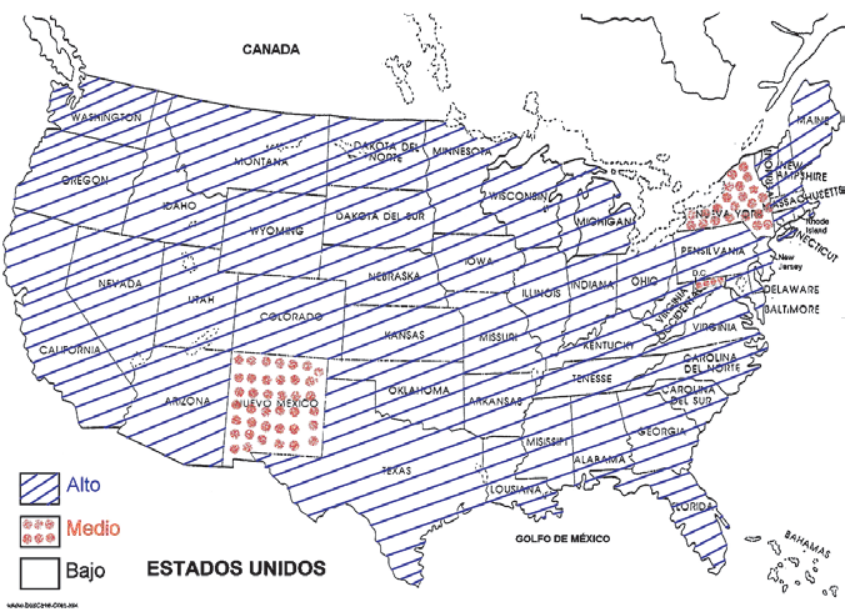

Fuente: Cuadro 2
La clasificación de las unidades territoriales hecha en el Cuadro No.2 puede combinarse en seis posibilidades, que se observan en el Cuadro No.3 y en el Mapa No.3: por un lado están los estados con Baja presencia latina en 2010 pero que entre los años 2000 y 2010 aumentaron a un ritmo medio o alto; por otro lado, aquellos con presencia intermedia de hispanos en 2010, que tuvieron un crecimiento medio o alto entre los años indicados; y finalmente los de presencia Alta de latinos en 2010, que además tuvieron un crecimiento medio o alto entre ambos años:

El Cuadro No.3 y el Mapa No.3 muestran que la mayor concentración de latinos en 2010 y su crecimiento más alto o mediano entre 2000 y 2010 estuvo ubicada en

Cuadro No. 3. Clasificación de los Estados, Según su Porcentaje de Población de Orígen Latino o "Hispánico" y Según el Porcentaje de Crecimiento de Ésta entre 2000 y 2019

\begin{tabular}{|c|c|c|c|c|c|}
\hline $\mathrm{B} / \mathrm{M}$ & $B / A$ & $\mathrm{M} / \mathrm{M}$ & $\mathrm{M} / \mathrm{A}$ & A/M & A/A \\
\hline Distrito de & Alabama & $\begin{array}{l}\text { New } \\
\text { York }\end{array}$ & Colorado & $\begin{array}{l}\text { New } \\
\text { Mexico }\end{array}$ & Arizona \\
\hline \multirow[t]{32}{*}{ Columbia } & Alaska & & Connecticut & & California \\
\hline & Arkansas & & Florida & & Nevada \\
\hline & Delaware & & Idaho & & Texas \\
\hline & Georgia & & Illinois & & \\
\hline & Hawaii & & Kansas & & \\
\hline & Indiana & & New Jersey & & \\
\hline & lowa & & Oregon & & \\
\hline & Kentucky & & Rhode Island & & \\
\hline & Louissiana & & Utah & & \\
\hline & Maine & & Washington & & \\
\hline & Maryland & & & & \\
\hline & Massachusetts & & & & \\
\hline & Michigan & & & & \\
\hline & Minnesota & & & & \\
\hline & Mississippi & & & & \\
\hline & Missouri & & & & \\
\hline & Montana & & & & \\
\hline & Nebraska & & & & \\
\hline & New Hampshire & & & & \\
\hline & North Carolina & & & & \\
\hline & North Dakota & & & & \\
\hline & Ohio & & & & \\
\hline & Oklahoma & & & & \\
\hline & Pennsylvania & & & & \\
\hline & South Carolina & & & & \\
\hline & South Dakota & & & & \\
\hline & Tennessee & & & & \\
\hline & Vermont & & & & \\
\hline & Virginia & & & & \\
\hline & West Virginia & & & & \\
\hline & Wisconsin & & & & \\
\hline & Wyoming & & & & \\
\hline Criterio & Valor & & Siglas & $\begin{array}{l}\% \text { de } \\
\text { Latinos } \\
\text { en } 2010\end{array}$ & $\begin{array}{l}\% \text { variación } \\
2000-10\end{array}$ \\
\hline $\begin{array}{l}\text { Bajo } \\
\text { Medio } \\
\text { Alto }\end{array}$ & $\begin{array}{l}<10 \% \\
10-24.99 \% \\
25 \% \text { ó más }\end{array}$ & & $\begin{array}{l}\text { B/M } \\
B / A \\
M / M\end{array}$ & $\begin{array}{l}\text { Bajo } \\
\text { Bajo } \\
\text { Medio }\end{array}$ & $\begin{array}{l}\text { Medio } \\
\text { Alto } \\
\text { Medio }\end{array}$ \\
\hline & & & $\begin{array}{l}\text { M/A } \\
\text { A/M } \\
\text { A/A }\end{array}$ & $\begin{array}{l}\text { Medio } \\
\text { Alto } \\
\text { Alto }\end{array}$ & $\begin{array}{l}\text { Alto } \\
\text { Medio } \\
\text { Alto }\end{array}$ \\
\hline
\end{tabular}

3. Sin embargo, en el Cuadro A del Anexo puede observarse que los porcentajes de cambio entre 2000 y 2010 de esas tres regiones son cercanos al límite que separa los de crecimiento alto con los intermedios: Nuevo México, 24.6\%; DC, 21.8\%; Nueva York, 19.2\% 
cinco estados de las regiones suroccidental y sur-central (California, Nevada, Arizona y Texas; seguidos de Nuevo México). La concentración mediana y el crecimiento alto o mediano en siete de las zonas noroccidental y central (Washington, Oregón, Idaho, Utah, Colorado, Kansas e Illinois) así como también en Florida (al sureste) y en cuatro del noreste (Connecticut, Rhode Island y Nueva Jersey; seguidos por Nueva York). El resto de los 33 estados tuvo una concentración baja de latinos en 2010 a pesar de haber tenido un crecimiento alto entre 2000 y 2010. El Distrito de Columbia presentó una concentración porcentualmente baja en 2010 y con crecimiento medio entre los dos años indicados.

\section{Los Centroamericanos en Estados Unidos}

4.1 Encuestas de 2009 y 2008 a la Población Hispana Residente

Las personas de ascendencia latina viviendo en los Estados Unidos en 2009 se estimaron en 48,348,144, de los

\section{Mapa No. 3. Estados Según Población Latina en 2010 y su Crecimiento Entre 2000 y 2010 (\%)}

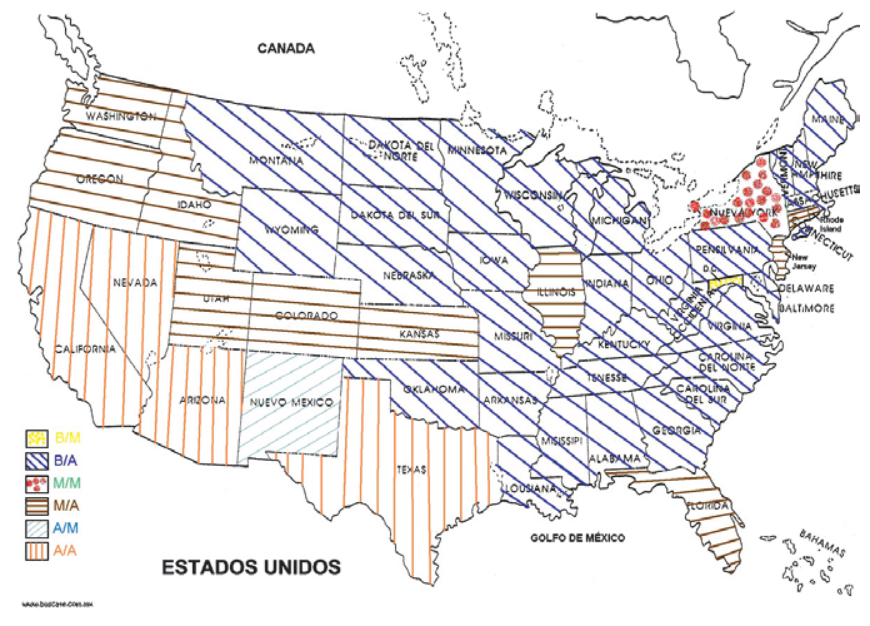

que 4,140,186 (8.6\%) se identificaron a sí mismas como de origen centroamericano (Cuadro No.4). De estos últimos, 64.7\% había nacido "fuera de los EUA o sus territorios" y ninguno de sus padres era ciudadano estadounidense. El 35.3\% complementario había nacido en EUA o era descendiente de un ciudadano de este país por nacimiento o naturalización. Esto significa que la migración de los centroamericanos es mayoritariamente reciente. Entre ellos, sólo los panameños escapan a esa tendencia, pues en su caso los nacidos en Estados Unidos son ligeramente superiores a quienes lo hicieron en Panamá. En ese mismo cuadro también se observa que la tendencia en el total de hispanos tiene proporciones a la inversa de la mayoría de centroamericanos: el 62.6\% nació en EUA y el 37.4\% en su respectivo país de ascendencia ${ }^{4}$, indicando que en su caso la migración data de más tiempo.

Del total de centroamericanos que vivían en Estados Unidos en 2009, la mayoría procede del triángulo norte: El Salvador (41.9\%), Guatemala (26.0\%) y Honduras (15.1\%) concentrando así a más de las cuatro quintas partes $(83 \%)$ del total de inmigrantes centroamericanos en EUA, ya sea al focalizar en las nuevas generaciones nacidas en EUA (81.1\%) o de la primera generación de inmigrantes nacidos en su respectivo país de ascendencia (84.1\%). (Cuadro No.4).

El $8.6 \%$ de centroamericanos que se encontraba entonces entre el total de hispanos varía al analizar la información por lugar de nacimiento: el total regional es de $14.8 \%$ de nacidos en su respectivo país de ascendencia y de $4.8 \%$ entre las generaciones nacidas en EUA (Cuadro No.4), mostrando nuevamente el peso cuantitativo de las primeras generaciones de inmigrantes. Quienes declararon ser originarios del triángulo norte centroamericano predominan en ambos casos: $3.8 \%$ de los $4.8 \%$ nacidos en EUA tenía ascendientes procedentes

4. Esa tendencia se debe principalmente a la población de origen mejicano, que constituyó el $65.6 \%$ del total de latinos analizados (31,673,700 de los 48,348,144 del total). En su caso, sólo $36.1 \%$ había nacido en México. Otras comunidades cuya menor proporción había nacido en su país de ascendencia fueron: España (13.5\%), "Otros sudamericanos" (49.6\%) y "Otros hispanos" (12\%), además de Panamá que ya está reportado en dicho cuadro (48.6\%) y Puerto Rico (1\%). En este último caso porque la definición de la encuesta define a este último como parte de los territorios de EUA. 
Cuadro No. 4. 2009 Centroamericanos en EUA, Según País de Ascendencia y Lugar de Nacimiento

\begin{tabular}{|c|c|c|c|c|c|c|c|c|c|c|}
\hline \multirow{2}{*}{$\begin{array}{l}\text { País de } \\
\text { Ascendencia }\end{array}$} & \multirow[t]{2}{*}{ Total } & \multicolumn{2}{|c|}{ Nacidos en } & \multirow{2}{*}{$\begin{array}{c}\text { Nacidos en } \\
\text { Extranjero (\%) }\end{array}$} & \multirow[b]{2}{*}{ Total } & \multicolumn{2}{|c|}{ Nacidos en } & \multirow[b]{2}{*}{ Total } & \multicolumn{2}{|c|}{ Nacidos en } \\
\hline & & EUA & Extranjero & & & EUA & Extranjero & & EUA & Extranjero \\
\hline Total CA & $4,140,186$ & $1,460,242$ & $2,679,944$ & 64.7 & $1,122.9$ & $1,164.2$ & $1,101.6$ & 8.6 & 4.8 & 14.8 \\
\hline Belice $\left(^{*}\right)$ & 31,912 & 13,513 & 18,399 & 57.7 & 8.7 & 10.8 & 7.6 & 0.1 & 0.0 & 0.1 \\
\hline Costa Rica & 131,331 & 50,032 & 81,299 & 61.9 & 35.6 & 39.9 & 33.4 & 0.3 & 0.2 & 0.4 \\
\hline El Salvador & $1,736,221$ & 647,368 & $1,088,853$ & 62.7 & 470.9 & 516.1 & 447.6 & 3.6 & 2.1 & 6.0 \\
\hline Guatemala & $1,077,412$ & 339,849 & 737,563 & 68.5 & 292.2 & 270.9 & 303.2 & 2.2 & 1.1 & 4.1 \\
\hline Honduras & 624,533 & 196,720 & 427,813 & 68.5 & 169.4 & 156.8 & 175.8 & 1.3 & 0.6 & 2.4 \\
\hline Nicaragua & 368,720 & 125,433 & 243,287 & 66.0 & 100.0 & 100.0 & 100.0 & 0.8 & 0.4 & 1.3 \\
\hline Panamá & 170,057 & 87,327 & 82,730 & 48.6 & 46.1 & 69.6 & 34.0 & 0.4 & 0.3 & 0.5 \\
\hline Total Hispanos & $48,348,144$ & $30,278,868$ & $18,069,276$ & 37.4 & & & & 100.0 & 100.0 & 100.0 \\
\hline
\end{tabular}

(*) Se ha asumido por Belice la categoría Other Central American

Fuente: Pew Hispanic Center tabulations of 2009 American Comunity Survey, 2009 Hispanic resident population; citado en: http://pewhispanic.org/files/factsheets/hispanics2009/Table\%207. pdf, recuperado el 19 de mayo de 2011.

de Guatemala, El Salvador u Honduras; mientras que también se identificaron con esos mismos tres países el $12.5 \%$ de los $14.8 \%$ de quienes habían nacido fuera de la unión norteamericana.

Por otra parte, el Cuadro No.5 muestra algunos indicadores de las condiciones de vida de la población latina residente en 2008 en los Estados Unidos, incluyendo a personas con ascendencia de esos tres países centroamericanos.

Este cuadro contiene información de 91.9\% de los latinos que vivían en los EUA según la encuesta de 2008, lo que evidencia su representatividad. Entre las 10 colectividades hispanas mayoritarias se encuentran las tres del triángulo norte centroamericano.
Además de reiterar la tendencia ya comentada sobre el origen inmigrante o nativo de estas poblaciones, el Cuadro No.5 muestra que la población con ascendencia de los tres países centroamericanos está entre la más joven y con menor nivel de instrucción con relación a la del resto de naciones latinas, como lo indican los porcentajes de quienes tienen diploma universitario o de secundaria ${ }^{5}$; asî como también con menor adaptación a su nuevo medio, pues ocupa los últimos lugares en cuanto al dominio del idioma inglés o contar con la ciudadanía.

A pesar de lo anterior, los originarios de esos tres países centroamericanos no ocupan los últimos lugares en cuanto a condiciones económicas y de vida, al comparar los diez grupos según el ingreso promedio del hogar ${ }^{6}$ o

Cuadro No. 5. 2008: Algunas Características de la Población de Ascendencia Hispana Viviendo en los Estados Unidos, para Algunas Nacionalidades

\begin{tabular}{|c|c|c|c|c|c|c|c|c|c|c|c|}
\hline Ascendencia & Población & $\begin{array}{l}\text { Nacidos } \\
\text { fuera } \\
\text { EUA (\%) a/ }\end{array}$ & $\begin{array}{l}\text { Promedio } \\
\text { de Edad } \\
\text { (Años) }\end{array}$ & $\begin{array}{c}\% \text { Sólo con } \\
\text { Secundaria } \\
\text { b/ }\end{array}$ & $\begin{array}{l}\text { Diploma } \\
\text { Universita- } \\
\text { rio (\%) }\end{array}$ & $\begin{array}{l}\text { Dominio } \\
\text { de Inglés } \\
(\%) \text { d }\end{array}$ & $\begin{array}{l}\text { Ciudada- } \\
\text { nos d/ } \\
(\%)\end{array}$ & $\begin{array}{l}\text { Ingreso } \\
\text { Mediodel } \\
\text { Hogar (\$) }\end{array}$ & $\begin{array}{l}\text { Viviendo en } \\
\text { Pobreza }(\%)\end{array}$ & $\begin{array}{l}\text { Sin seguro } \\
\text { de } \\
\text { Salud (\%) }\end{array}$ & $\begin{array}{c}\text { Propietarios } \\
\text { de Vivi- } \\
\text { enda( } \%)\end{array}$ \\
\hline Total Hispanos & $46,822,000$ & 38.1 & 27 & 26.0 & 12.9 & 62.7 & 72.8 & 41,754 & 20.7 & 31.7 & 49.1 \\
\hline México & $30,746,000$ & 37.0 & 25 & 25.5 & 9.1 & 61.6 & 71.1 & 40,736 & 22.3 & 34.8 & 50.5 \\
\hline Puerto Rico & $4,151,000$ & 1.1 & 29 & 28.8 & 16.0 & 80.5 & 99.4 & 40,736 & 22.6 & 15.6 & 40.3 \\
\hline Cuba & $1,631,000$ & 60.1 & 41 & 26.7 & 25.1 & 58.3 & 74.9 & 43,587 & 13.2 & 22.7 & 59.7 \\
\hline El Salvador & $1,560,000$ & 64.7 & 29 & 23.4 & 8.4 & 44.2 & 54.2 & 43,791 & 15.4 & 38.9 & 46.0 \\
\hline R.Dominicana & $1,334,000$ & 57.3 & 29 & 25.7 & 15.6 & 53.4 & 69.9 & 35,644 & 23.2 & 23.4 & 28.3 \\
\hline Guatemala & 986,000 & 69.4 & 28 & 22.1 & 8.8 & 39.1 & 47.1 & 41,754 & 20.6 & 47.9 & 35.6 \\
\hline Colombia & 882,000 & 66.5 & 36 & 26.9 & 30.3 & 57.5 & 65.9 & 49,901 & 11.0 & 26.4 & 53.0 \\
\hline Honduras & 608,000 & 68.6 & 28 & 22.3 & 10.3 & 39.7 & 46.4 & 36,662 & 21.5 & 49.3 & 33.9 \\
\hline Ecuador & 591,000 & 66.4 & 32 & 29.0 & 18.2 & 49.1 & 58.3 & 49,392 & 13.5 & 34.7 & 40.3 \\
\hline Perú & 519,000 & 69.3 & 35 & 29.7 & 29.8 & 55.1 & 60.0 & 51,734 & 9.5 & 30.2 & 50.1 \\
\hline
\end{tabular}

a/ Nacidos fuera EUA o sus territorios, y ningún padre era ciudadano EUA

c/ Hablan inglés en el hogar, o hablan inglés muy bien (con edad de 5 años ó más)

b/ Con edad de 25 años o más, teniendo diploma de secundaria solamente

e/ Jefes de hogar viviendo en hogares propios

Fuente: Pew Hispanic Center, Data \& Resources: Country of Origin Profiles. http://pewhispanic.org/data/origins/ recuperado el 23 de mayo de 201

5. La situación real podría ser aún peor de la sugerida por este cuadro, pues él no muestra la población que no tiene ni siquiera diploma secundario.

6. Excepto los inmigrantes de ascendencia hondureña, que quedan en el penúltimo lugar. 
el porcentaje de hogares viviendo en condiciones de pobreza. Pero en indicadores sociales destacan por no contar con seguro de salud o por no ser propietarios de la vivienda donde habitan. ${ }^{7}$

\subsection{Censo de Población de 2010}

En el Mapa No.4 se presenta la nacionalidad centroamericana que según el censo de EUA hecho en 2010 fue mayoritaria en cada uno de sus estados, observándose los de Guatemala y El Salvador son los más numerosos en la mayor parte de estados (son mayoría en 27 y 22 estados, respectivamente), mientras que los de Honduras lo son en Luisiana y los de Nicaragua en Florida.

Por otra parte, el Cuadro No.6 y los Mapas A (En anexo) muestran los estados donde se concentran más los emigrantes de cada país centroamericano: ${ }^{8}$ en sólo siete estados habita $72.9 \%$ del total de emigrados centroamericanos $^{9}$. Al analizar para cada nacionalidad se constata que en sólo cinco estados vive $65.6 \%$ de beliceños ${ }^{10}$, $64.7 \%$ de costarricenses ${ }^{11}, 72.5 \%$ de salvadoreños ${ }^{12}$ y $58 \%$
Mapa No. 4. 2010: Nacionalidad Porcentualmente más Numerosa en Cada Estado de los EUA, Entre Todos los Centroamericanos

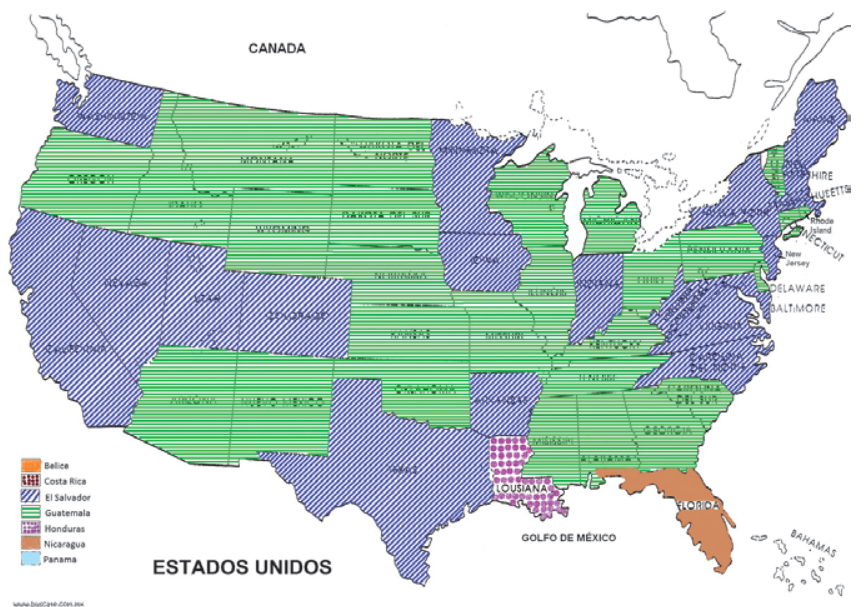

Fuente: Cuadro C del Anexo

de guatemaltecos ${ }^{13}$; por su parte, $74.1 \%$ de hondureños se concentra en ocho estados ${ }^{14}$; mientras que $73.4 \%$ de nicaragüenses lo hace en sólo tres estados ${ }^{15}$; y seis son los estados donde reside $63.1 \%$ de panameños ${ }^{16}$. Si se toma

Cuadro No. 6. Clasificación de los Estados Según la Concentración en Ellos de los Emigrantes de Países Centroamericanos

\begin{tabular}{|c|c|c|c|c|}
\hline País & Alto & Medio & Suma $(\%)$ & Diferencia (\%) ${ }^{1}$ \\
\hline Centroamérica & California (28.3\%) & $\begin{array}{l}\text { Nueva York }(8.8 \%) \text {, Virginia (5.2\%), Maryland }(4.9 \%) \text {, } \\
\text { N. Jersey }(4.4 \%)\end{array}$ & 72.9 & 27.1 \\
\hline Belice & California (38.0\%) & $\begin{array}{l}\text { Nueva York (9.3\%), Texas (8.4\%), Florida (5.4\%), } \\
\text { Virginia }(4.5 \%)\end{array}$ & 65.6 & 34.4 \\
\hline Costa Rica & $\begin{array}{l}\text { California }(17.8 \%) \text {, Forida }(16.4 \%) \text {, } \\
\text { N. Jersey }(15.8 \%)\end{array}$ & Nueva York $(9.2 \%)$, Texas $(5.5 \%)$ & 64.7 & 35.3 \\
\hline El Salvador & California (34.8\%) & $\begin{array}{l}\text { Nueva York (9.2\%), Maryland (7.5\%), } \\
\text { Virginia }(7.5 \%)\end{array}$ & 72.5 & 27.5 \\
\hline Guatemala & California (31.9\%) & $\begin{array}{l}\text { Florida }(8.0 \%) \text {, Nueva York (7.1\%), Texas }(6.3 \%) \\
\text { N. Jersey }(4.7 \%)\end{array}$ & 58.0 & 42.0 \\
\hline Honduras & Florida (16.9\%) & $\begin{array}{l}\text { N. Jersey }(5.8 \%) \text {, N. Carolina (4.9\%), Luisiana (4.8\%), } \\
\text { Virginia }(4.8 \%)\end{array}$ & 74.1 & 25.9 \\
\hline Nicaragua & Florida (38.8\%), California (28.8\%) & Texas $(5.7 \%)$ & 73.4 & 26.6 \\
\hline Panamá & Florida (17.4\%), Nueva York (17.0\%) & $\begin{array}{l}\text { Texas }(8.5 \%) \text {, Georgia }(5.2 \%) \text {, } \\
\text { Virginia }(4.3 \%)\end{array}$ & 63.1 & 36.9 \\
\hline
\end{tabular}

7. En este último caso se exceptúa a los salvadoreños, que ocupan una posición intermedia.

8. Se ha considerado que un estado tiene concentración "Alta" de una nacionalidad centroamericana dada si concentra 15\% ó más de los emigrantes de esa nacionalidad. Será "Medio" si concentra entre 10 y 14.9\%, "Baja” entre 4 y 9.9\% y "Muy Baja” si es inferior a 4\%.

9. El conjunto de centroamericanos se concentran en California, Florida, Texas, Nueva York, Virginia, Maryland y Nueva Jersey.

10. $65.6 \%$ de beliceños viven en California, Nueva York, Texas, Florida y Virginia.

11. $64.7 \%$ de costarricenses están concentrados en California, Florida, Nueva Jersey, Nueva York y Texas.

12. $72.5 \%$ de salvadoreños habitan en California, Texas, Nueva York, Maryland y Virginia.

13. $58 \%$ de guatemaltecos viven en California, Florida, Nueva York, Texas y Nueva Jersey.

14. $74.1 \%$ de hondureños residen en Florida, Texas, California, Nueva York, Nueva Jersey, Carolina del Norte, Luisiana y Virginia.

15. $73.4 \%$ de nicaragüenses se concentran en Florida, California y Texas.

16. $63.1 \%$ de panameños habitan en Florida, Nueva York, California, Texas, Georgia y Virginia.

17. La columna de "Diferencia" en el Cuadro 6 indica el porcentaje de cada una de las nacionalidades que vive en el resto de los estados de la unión norteamericana; es decir, los que no están mencionados en este cuadro para cada nacionalidad centroamericana. 
en cuenta que los Estados Unidos están formados por 50 estados y el Distrito de Columbia, se constata que los centroamericanos están concentrados principalmente en pocos territorios de dicha unión.

\subsection{Las Condiciones de Vida Promedio en los Lugares de Origen y de Destino}

Para los países de CA y los diez estados de los EUA hacia donde más emigran los centroamericanos -que se identificaron en el Cuadro No.6 y Mapas A del Anexo- se presenta en el Cuadro No.7 algunos indicadores sociales y económicos, para comparar esas condiciones promedio que estos emigrantes dejan atrás en sus países de origen y las que encuentran en los estados de destino. Puede asumirse que las condiciones de vida de estos migrantes son peores que los promedios indicados en el Cuadro No.7, tanto en el país de origen como en el estado de destino, pero esa información puede dar una idea aproximada sobre las condiciones de vida promedio en ambos lugares, así como también de los cambios experimentados por quien migra de un lugar a otro.

Se seleccionaron indicadores significativos para representar las condiciones de vida de los lugares a comparar, entre los pocos que estuvieron disponibles tanto para los países centroamericanos como para los estados de EUA que tienen mayor concentración de dicha población. Es necesario ser prudente al compararlos y especialmente al sacar conclusiones, pues no sólo los conceptos puede ser diferentes sino que también la calidad en la obtención de los indicadores puede variar, tanto entre los países centroamericanos entre sí, como entre éstos y los estados de destino; por lo que las conclusiones que se derivan de esas comparaciones deben considerarse solamente como aproximaciones de lo que puede significar el cambio de vida de los emigrantes centroamericanos al llegar a los estados de la unión norteamericana, o al regresar a sus respectivos países de origen.
Los indicadores utilizados son ${ }^{18}$ :

\begin{tabular}{|c|c|c|}
\hline \multicolumn{3}{|c|}{ Indicadores } \\
\hline \multirow{2}{*}{ 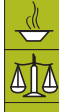 } & Línea de la pobreza & Población bajo línea de pobreza (en porcentaje) \\
\hline & Concentración Gini Ingresos & Índice de Concentración de Gini para ingresos (en por ciento) \\
\hline & Paridad Poder Adquisitivo & $\begin{array}{l}\text { Producto Interno Bruto per capita, según Paridad del Poder } \\
\text { Aquisitivo, PPA (en \$EUA) }\end{array}$ \\
\hline \multirow{2}{*}{ 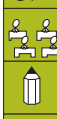 } & \multirow{2}{*}{$\begin{array}{l}\text { Alumnos por maestro } \\
\text { Prrimaria } \\
\text { Mayores de } 25 \text { años con al } \\
\text { menos secundaria completa }\end{array}$} & $\begin{array}{l}\text { Número de alumnos por maestro en los centros de enseñanza } \\
\text { primaria }\end{array}$ \\
\hline & & $\begin{array}{l}\text { Porcentaje de personas mayores de } 25 \text { años con al menos educa- } \\
\text { ción secundaria completa }\end{array}$ \\
\hline Uת & $\begin{array}{l}\text { Mortalidad Menores } \\
\text { de } 5 \text { años }\end{array}$ & $\begin{array}{l}\text { Tasa de mortalidad de menores de cinco años (por mil nacidos } \\
\text { vivos) }\end{array}$ \\
\hline 9 & \multirow{2}{*}{$\begin{array}{l}\text { Mortalidad Materna } \\
\text { Esperanza de vida al nacer }\end{array}$} & Tasa de mortalidad materna (por cien nacidos vivos) \\
\hline & & Esperanza de vida al nacer (en años) \\
\hline
\end{tabular}

El Cuadro No.7 permite elaborar los Cuadros E, F y G del Anexo, para observar cómo cambiarían las condiciones socioeconómicas de los migrantes si ellos experimentaran las condiciones de vida promedio de sus respectivas regiones de origen y de destino.

En el Cuadro E del Anexo se presentan los cambios que experimentarían en sus condiciones de vida los emigrantes de cada país centroamericano al inmigrar a los cuatro estados que en el Cuadro No.6 se identificaron como ejerciendo una concentración "Alta" sobre ellos. Se ha indicado además para cada uno de esos cuatro estados el porcentaje de nacionales de cada país centroamericano que viven ahí, con respecto al total de las personas de esa nacionalidad que viven en el conjunto de EUA. ${ }^{19}$

Los cambios de los indicadores socioeconómicos pueden interpretarse de la siguiente forma, ejemplificándolo para facilitar la comprensión con el caso de los hondureños viviendo en el estado de Florida (Cuadro No.8), donde se concentra $16.9 \%$ de los inmigrantes de esa nacionalidad:

- Ganancia en puntos porcentuales en línea de pobreza: se refiere a cuántos puntos porcentuales se modifica el indicador entre un lugar y otro. Como los indicadores en comparación son porcentajes de población que vive bajo línea de pobreza en lugares diferentes, la comparación debe tomarse con precaución principalmen-

18. El autor agradece a Ana Karenina Cardona Reyes su cooperación en elaborar la representación gráfica que aparece en esta sección. Se han utilizado algunas de las figuras empleadas por los Objetivos de Desarrollo del Milenio.

19. Lo que a su vez proviene del Cuadro 6 y del Cuadro D del Anexo. Para ejemplificar el significado de ese porcentaje puede verse la llamada que está al pie del Cuadro 8. 
te porque los conceptos y las líneas de pobreza son diferentes en cada lugar. Sin embargo, permite dar una idea de la situación que en este rubro deja atrás el emigrante y del que lo recibe en su lugar de llegada. Por ejemplo, el Cuadro No.7 muestra que un emigrante hondureño deja un país con 60\% de la población viviendo bajo la línea de pobreza, y cuando llega a Florida encuentra un estado donde $16.5 \%$ de sus habitantes enfrentan tal situación. Con todas las limitaciones que esas cifras tienen para ser comparadas, la diferencia de 43.5 puntos porcentuales (pp) en el Cuadro No.8 da cierta idea del cambio de ambiente que esa persona experimenta en ese rubro. A

\section{Cuadro No. 7. Algunos Indicadores Socioeconómicos de los Países Centroamericanos, EUA y Ciertos Estados en los últi- mos Años}

\begin{tabular}{|c|c|c|c|c|c|c|c|c|c|c|c|c|c|c|c|c|c|c|}
\hline \multirow[t]{2}{*}{ Indicador } & \multirow[t]{2}{*}{ Belice } & \multirow{2}{*}{$\begin{array}{l}\text { Guate- } \\
\text { mala }\end{array}$} & \multirow{2}{*}{$\begin{array}{l}\text { El } \\
\text { Salva- } \\
\text { dor }\end{array}$} & \multirow{2}{*}{$\begin{array}{l}\text { Hon- } \\
\text { duras }\end{array}$} & \multirow{2}{*}{$\begin{array}{l}\text { Nica- } \\
\text { ragua }\end{array}$} & \multirow{2}{*}{$\begin{array}{l}\text { Costa } \\
\text { Rica }\end{array}$} & \multirow{2}{*}{$\begin{array}{c}\text { Pana- } \\
\text { má }\end{array}$} & \multicolumn{10}{|c|}{ Estado } & \multirow[b]{2}{*}{ EUA } \\
\hline & & & & & & & & $\begin{array}{l}\text { Califor- } \\
\text { nia }\end{array}$ & $\begin{array}{l}\text { Caroli- } \\
\text { na del } \\
\text { Norte }\end{array}$ & Florida & Georgia & $\begin{array}{l}\text { Louisia- } \\
\text { na }\end{array}$ & $\begin{array}{l}\text { Mary- } \\
\text { land }\end{array}$ & $\begin{array}{l}\text { New } \\
\text { Jersey }\end{array}$ & $\begin{array}{l}\text { New } \\
\text { York }\end{array}$ & Texas & Virginia & \\
\hline $\begin{array}{l}\text { Población bajo línea } \\
\text { de pobreza nacional } \\
(\%)(a)\end{array}$ & 33.5 & 51 & 37.8 & 60 & 46.2 & 21.7 & - & 15.8 & 17.5 & 16.5 & 17.9 & 18.7 & 9.9 & 10.3 & 14.9 & 17.9 & 11.1 & 15.3 \\
\hline Gini de Ingresos 2011 & $\ldots$ & 53.7 & 46.9 & 57.7 & 52.3 & 50.3 & 52.3 & 47.11 & 46.4 & 47.44 & 46.88 & 47.55 & 44.33 & 46.4 & 49.9 & 46.99 & 45.9 & 40.8 \\
\hline $\begin{array}{l}\text { PIB per capita } \\
\text { 2010(PPA en US\$) (b) }\end{array}$ & 4,064 & 2,862 & 3,426 & 2,026 & 1,132 & 7,691 & 7,589 & 46,369 & 39,808 & 35,735 & 37,271 & 42,949 & 45,780 & 49,845 & 53,338 & 43,799 & 47,430 & 47,200 \\
\hline $\begin{array}{l}\text { En Primaria: Alumnos } \\
\text { por Maestro }\end{array}$ & 22.6 & 29.4 & 32.6 & 33.3 & 29.2 & 18.4 & 23.6 & 20.9 & 14.4 & 15.6 & 13.9 & 14 & 14.1 & 12 & 12 & 14.4 & 11.7 & 13.9 \\
\hline \multicolumn{19}{|l|}{$\begin{array}{l}\text { Mayores de } 25 \\
\text { años con al menos } \\
\text { educación secundaria } \\
\text { completa }(c) \text { : }\end{array}$} \\
\hline - Ambos Sexos & - & - & - & - & - & - & & 80.6 & 85.3 & 83.9 & 82.2 & 88.2 & 87.4 & 84.7 & & & & \\
\hline - Hombres & 35.2 & 21 & 47.5 & 36.3 & 44.7 & 52.8 & & & & & & & & & 84.3 & 79.9 & 86.6 & 85.3 \\
\hline - Mujeres & 32.8 & 15.6 & 40.5 & 31.9 & 30.8 & 54.4 & & & & & & & & & & & & \\
\hline $\begin{array}{l}\text { Tasa de Mortalidad } \\
\text { (Menores de } 5 \text { años)(d) }\end{array}$ & 18 & 40 & 17 & 30 & 26 & 11 & 23 & 5.3 & 8.8 & 14.1 & 8.2 & 6.6 & 7.3 & 5.2 & 5.8 & 6.6 & 7.5 & \\
\hline $\begin{array}{l}\text { Tasa de Mortalidad } \\
\text { Materna (e) }\end{array}$ & 94 & 110 & 110 & 110 & 100 & 44 & 71 & 13 & 23 & 21 & 11 & 22 & 17 & 24 & 28 & 8 & 16 & 24 \\
\hline $\begin{array}{l}\text { Esperanza de Vida al } \\
\text { Nacer (Años) } 2011\end{array}$ & 76,1 & 71.2 & 72.2 & 73.1 & 74 & 79.3 & 76.1 & 77.9 & 75.8 & 77.5 & 75.3 & 74.2 & 76.3 & 77.5 & 77.7 & 76.7 & 76.8 & 78.5 \\
\hline
\end{tabular}

Fuente: UNDP (2011), Informe sobre Desarrollo Humano 2011. Sostenibilidad y Equidad: Un Mejor Futuro para Todos. Nueva York: UNDP, Anexo Estadístico, Cuadros Nos. 1, 2, 3, 4, 5, 7, 8, 9, 10.

\section{Bibliografía Complementaria:}

Foundation, H. J. (20 de 12 de 2010). Kaiser State Health Facts. Recuperado el 18 de 11 de 2011, de State Health Facts.org: http://www.statehealthfacts.org/comparemaptable.jsp?ind=37\&cat=2 Index Mundi. (09 de Noviembre de 2011). Index Mundi. Recuperado el 1 de Enero de 2011, de Index Mundi: http://www.indexmundi.com

Leduc, T. (04 de 11 de 2011). World Life Expectancy. Recuperado el 06 de 2011, de World Life Expectancy: http://www.worldlifeexpectancy.com/usa/north-carolina-life-expectancy

Sondik, E. J. (09 de Noviembre de 2011). Centers For Disease control and Prevention. Recuperado el 13 de Julio de 2009, de http://www.cdc.gov/nchs/data/databriefs/db64.htm

United States Government. (01 de 01 de 2010). U.S Census Bureau. Recuperado el 16 de 11 de 2011, de U.S Census Bureau: http://factfinder2.census.gov/faces/tableservices/jsf/pages/productview. xhtml?pid=ACS_10_1YR_B19083\&prodType=table

Oficina de Censos E.E.U.U. (2011). Anuario Estadístico de los Estados Unidos. Recuperado el 14 de 11 de 2011, de 594 - tasa de participación en la fuerza laboral: 2010 : http://www.census.gov/compendia/statab/cats/labor force employment earnings.html

American Community Survey Briefs. Poverty. (2010). Pobreza 2009- 2010. Recuperado el 14 de 11 de 2011, de http://www.census.gov/prod/2011 pubs/acsbr10-01.pdf

Oficina de Censos E.E.U.U. (2011). Anuario Estadístico de los Estados Unidos. Recuperado el 14 de 11 de 2011, de 594 - tasa de participación en la fuerza laboral: 2010 : http://www.census.gov/compendia/statab/cats/labor_force_employment_earnings.html

Resumen Anuario Estadístico E.E.U.U. Recuperado el 14 de 11 de 2011, de 709 - Los individuos y las familias por debajo del nivel de la pobreza: http://www.census.gov/compendia/statab/cats/income_expenditures poverty wealth.html

American Community Survey Briefs. Poverty. (2010). Pobreza 2009- 2010. Recuperado el 14 de 11 de 2011, de http://www.census.gov/prod/2011pubs/acsbr10-01.pdf

Oficina de Censos E.E.U.U. (2011). Resumen Anuario Estadístico E.E.U.U. Recuperado el 13 de 11 de 2011, de 233 - Nivel de Educación por el Estado: http://www.census.gov/compendia/statab/cats/ education.html

Oficina de Censos de los estados Unidos. «Anuario Estadístico de los Estados Unidos 2012.» Vers. Electrónica. 17 - Las tasas de dependencia de edad por el estado. 2011. http://www.census.gov/ compendia/statab/ (último acceso: 27 de 11 de 12).

U.S. Census Bureaud. (1 de 12 de 2011). Estimaciones de la población 2009. Recuperado el 10 de 12 de 2011, de http://factfinder.census.gov/servlet/GCTTable?-ds_name=PEP_2009_EST\&-mt_ name=PEP 2009 EST GCTT2R U40SA\&-format=US-40|U-40Sa|U-40Sb|U-40Sc|U-40Sd|U-40Se|U-40Sf $\mid$ U-40Sg $\mid$ U-40Sh|US-40S\&-CONTEXT=gct\&-geo id=

Abstract, T. S. (08 de diciembre de 2009). U.S. Census Bureau. Recuperado el 20 de noviembre de 2011, de http://www.census.gov/compendia/statab/cats/population.html

Anuales, C. d. (12 de septiembre de 2011). Index Mundi. Recuperado el 5 de diciembre de 2011, de http://www.indexmundi.com/g/g.aspx?c=bh\&v=67\&l=es

Change, P. D. (22 de diciembre de 2010). United States Census Bureau. Recuperado el 25 de noviembre de 2011, de http://www.census.gov/prod/cen2010/briefs/c2010br-01.pdf

Foundation, H. J. (15 de diciembre de 2009). StateHealthFacts.org . Recuperado el 28 de noviembre de 2011, de http://www.statehealthfacts.org/comparetable.jsp?ind=502\&cat=11\&sub=118\&yr= 218\&typ $=2 \&$ sort $=a$

PNUD. (12 de diciembre de 2009). Indicadores Internacionales sobre Desarrollo Humano. Recuperado el 30 de noviembre de 2011, de http://hdrstats.undp.org/es/indicadores/38006.html State, C. S. (19 de octubre de 2011). U.S. Government Spending. Recuperado el 30 de Noviembre de 2011, de http://www.usgovernmentspending.com/compare_state_spending_2011 p20a Statistics, U. (30 de diciembre de 2005). InfoPlease. Recuperado el 23 de noviembre de 2011, de http://www.infoplease.com/ipa/A0005128.html

Rickety. (12 de diciembre de 2006). Rickety - United States Total Fertility Rate Increases. Recuperado el 15 de diciembre de 2011, de http://www.rickety.us/2009/01/united-states-fertility/Wo rld L Life Expectancy. (22 de octubre de 2011). Recuperado el 07 de diciembre de 2011, de http://www.worldlifeexpectancy.com/usa/north-carolina-child-death-rate 
eso se refiere el "gana 43.5 pp en línea de pobreza" que figura en este último cuadro y en el Cuadro E del Anexo, que le sirve como fuente.

- Igual reserva debe tenerse al comparar el Índice de Concentración de Gini para el Ingreso. Utilizando nuevamente el ejemplo de los emigrantes hondureños hacia la Florida, la frase "Gana 10.3 pp en menor concentración Gini Ingresos" en el Cuadro No. $8^{20}$ se refiere al hecho que una persona hondureña pasa de vivir en un país con Índice de Concentración de Gini de 57.7 \% ${ }^{21}$ y migra al estado de la Florida que tiene 47.4\%22. Ello significa un nuevo ambiente con una menor concentración del ingreso en 10.3 pp.

- En el mismo Cuadro No.8 el cambio de los otros indicadores ocurre en las unidades correspondientes. Así, manteniendo el ejemplo entre Honduras y Florida:

- El PIB per cápita en Paridad del Poder Adquisitivo de dichos emigrantes pasa de $\$ 2,026$ a otro con $\$ 35,735$, con una diferencia de $\$ 33,709$.

- Alumnos por maestro en escuelas primarias: Pasa de aulas con 33.3 niños en promedio a otro ambiente con 15.6, por lo que "gana" tener a sus hijos en aulas donde el maestro atiende un grupo menor de alumnos (17.7 niños menos).

- El porcentaje de población mayor de 25 años con al menos instrucción secundaria completa es un indicador sobre la competitividad de la mano de obra de una región. Continuando el mismo ejemplo, puede observarse que un emigrante hondureño que llega a Florida gana 49.9 PP22, al pasar de un país donde 36.3\% de los hombres y $31.9 \%$ de las mujeres ha concluido la educación secundaria, a un estado donde lo hace el $83.9 \%$ de dicha población.

- En el Cuadro No.8 se compara también la situación de la mortalidad de los menores de 5 años, medida por la tasa respectiva. Como en los puntos anteriores, los hijos menores de 5 años de los emigrantes hondureños
Cuadro No. 8. Ejemplo de un Estado con Alta Concentración de Centroamericanos: Modificación de Indicadores Socioeconómicos Prevalecientes en su Respectivo País de Origen con Respecto a los de Florida $\left(^{*}\right)$

\begin{tabular}{|c|c|c|c|c|c|c|c|c|c|}
\hline & 8 & dl & هـ & (2) & $\frac{8}{8}$ & (II) & $\frac{\varpi}{\pi}$ & $\stackrel{0}{3}$ & \\
\hline Belice & ---- & & & & & & & & \\
\hline Costa Rica & $16.4 \%$ & $\begin{array}{c}\text { Gana } \\
5.2 \mathrm{pp}\end{array}$ & $\begin{array}{c}\text { Gana } \\
2.9 \mathrm{pp}\end{array}$ & $\$ 28,044$ & $\begin{array}{c}2.8 \\
\text { Menos }\end{array}$ & $\begin{array}{c}\text { Gana } \\
30.9 \mathrm{pp}\end{array}$ & $\begin{array}{c}\text { Baja } \\
3.1 \mathrm{pp}\end{array}$ & $\begin{array}{c}\text { Baja } \\
23 \mathrm{pc}\end{array}$ & $\begin{array}{c}\text { Pierde } \\
1.8\end{array}$ \\
\hline El Salvador & ---- & & & & & & & & \\
\hline Guatemala & ---- & & & & & & & & \\
\hline Honduras & $16.9 \%$ & $\begin{array}{c}\text { Gana } \\
43.5 \mathrm{pp}\end{array}$ & $\begin{array}{c}\text { Gana } \\
10.3 p p\end{array}$ & $\$ 33,709$ & $\begin{array}{c}17.7 \\
\text { Menos }\end{array}$ & $\begin{array}{l}\text { Gana } \\
49.9 \mathrm{pp}\end{array}$ & $\begin{array}{c}\text { Baja } \\
15.9 \text { pp }\end{array}$ & $\begin{array}{c}\text { Ваја } \\
89 \text { pc }\end{array}$ & $\begin{array}{c}\text { Gana } \\
4.4\end{array}$ \\
\hline Nicaragua & $38.8 \%$ & $\begin{array}{c}\text { Gana } \\
29.7 \mathrm{pp}\end{array}$ & $\begin{array}{c}\text { Gana } \\
4.9 p p\end{array}$ & $\$ 34,603$ & $\begin{array}{c}13.6 \\
\text { Menos }\end{array}$ & $\begin{array}{c}\text { Gana } \\
45.9 \mathrm{pp}\end{array}$ & $\begin{array}{c}\text { Baja } \\
11.9 \mathrm{pp}\end{array}$ & $\begin{array}{c}\text { Baja } \\
79 \text { pc }\end{array}$ & $\begin{array}{c}\text { Gana } \\
3.5\end{array}$ \\
\hline Panamá & $17.4 \%$ & & $\begin{array}{c}\text { Gana } \\
4.9 \mathrm{pp}\end{array}$ & $\$ 28,146$ & $\begin{array}{c}8 \\
\text { Menos }\end{array}$ & & $\begin{array}{c}\text { Baja } \\
8.9 \mathrm{pp}\end{array}$ & $\begin{array}{c}\text { Baja } \\
50 \mathrm{pc}\end{array}$ & $\begin{array}{c}\text { Gana } \\
1.4\end{array}$ \\
\hline
\end{tabular}

${ }^{*}$ ) Ver significado de los símbolos de los indicadores al inicio de la sección 4.3. La primer columna en este cuadro no es un indicador, sino que significa el porcentaje de emigrantes de cada país centroamericano que vive en el estado de la Florida. Por ejemplo: $16.9 \%$ de todos los emigrantes hondureños que viven en los EUA fueron enumerados en la Florida.

Fuente: Cuadro E del Anexo, basado a su vez en los Cuadros 6 y 7.

pasan de un ambiente donde prevalece una mortalidad de 30 por mil habitantes a otro con 14.1 por mil, ganando así en 15.9 puntos por mil la reducción de la acción de la mortalidad sobre la población en esas edades.

- La comparación de las tasas de mortalidad maternas también muestra un importante descenso de ese riesgo en las mujeres emigrantes: para el ejemplo de las hondureñas en Florida pasa de una tasa de 110 a 21 por cien mil nacidos vivos, ganando así al residir en un ambiente con 89 puntos por cien mil más bajo.

- En el caso de la esperanza de vida al nacer, los condicionantes de la mortalidad diferentes en los dos lugares hacen que un emigrante hondureño pase de 73.1 a 77.5 años en Florida, ganando así 4.4 años de vida en promedio.

La comparación entre Honduras y Florida es sólo un ejemplo para facilitar la interpretación de los valores que

20. Así como en el Cuadro E del Anexo, que le sirve de base.

21. Ver Cuadro No.7.

22. De este indicador sólo se obtuvo información por género en el caso de los países centroamericanos y para ambos sexos en el caso de los estados de EUA. Para no desperdiciar un indicador tan importante se obtuvo un promedio aproximado con la información por sexo en el caso de los países para compararlo con el valor para ambos sexos en los estados. 
figuran en el Cuadro E del Anexo, donde evidentemente pueden consultarse los valores de los emigrantes de otros países de origen así como otros estados de destino.

En ese Cuadro E puede observarse que quienes salieron de los países centroamericanos y se concentraron en los estados de concentración "Alta"23 es decir: California, Florida, Nueva Jersey y Nueva York logran ambientes donde prevalecen mejores condiciones socioeconómicas, exceptuando el caso de la esperanza de vida al nacer de los costarricenses en California -donde perderían 1.4 añosy en Florida y Nueva Jersey, donde perderían 1.8 años. Otra excepción se observa en el caso de los salvadoreños en California, pues según las estadísticas de dicho país tiene una concentración del ingreso menor que el estado mencionado en 0.2 pp. En el Cuadro No.9 a continuación se presentan las modificaciones de esos indicadores

\section{Cuadro 9. Otros Estados con Alta Concentración de Centroamericanos: Modificación de Indicadores Socioeconómicos en su País de Origen Respecto a los de California, N. Jersey y N. York(*)}

\section{California}

\begin{tabular}{|c|c|c|c|c|c|c|c|c|c|}
\hline & 8 & $\stackrel{d l}{\longleftarrow}$ & बूش & (2) & $\frac{8}{b}$ & (11) & $\frac{\bullet}{\pi}$ & $\stackrel{3}{3}$ & \\
\hline Belice & $38 \%$ & $\begin{array}{c}\text { Gana } \\
17 \mathrm{pp}\end{array}$ & & $\$ 42,325$ & $\begin{array}{c}1.7 \\
\text { Menos }\end{array}$ & $\begin{array}{c}\text { Gana } \\
47.6 \mathrm{pp}\end{array}$ & $\begin{array}{c}\text { Baja } \\
12.7 p p\end{array}$ & $\begin{array}{c}\text { Baja } \\
81 \text { pc }\end{array}$ & $\begin{array}{c}\text { Gana } \\
1.8\end{array}$ \\
\hline Costa Rica & $17.8 \%$ & $\begin{array}{c}\text { Gana } \\
5.9 \mathrm{pp}\end{array}$ & $\begin{array}{c}\text { Gana } \\
3.2 \mathrm{pp}\end{array}$ & $\$ 38,678$ & $\begin{array}{l}2.5 \\
\text { Más }\end{array}$ & $\begin{array}{c}\text { Gana } \\
21.6 \mathrm{pp}\end{array}$ & $\begin{array}{c}\text { Baja } \\
5.7 \mathrm{pp}\end{array}$ & $\begin{array}{c}\text { Baja } \\
31 \text { pc }\end{array}$ & $\begin{array}{c}\text { Pierde } \\
1.4\end{array}$ \\
\hline El Salvador & $34.8 \%$ & $\begin{array}{c}\text { Gana } \\
22 \mathrm{pp}\end{array}$ & $\begin{array}{l}\text { Pierde } \\
0.2 \mathrm{pp}\end{array}$ & $\$ 42,943$ & $\begin{array}{c}11.7 \\
\text { Menos }\end{array}$ & $\begin{array}{c}\text { Gana } \\
37.6 \mathrm{pp}\end{array}$ & $\begin{array}{c}\text { Baja } \\
11.7 \mathrm{pm}\end{array}$ & $\begin{array}{l}\text { Baja } \\
97 \mathrm{pc}\end{array}$ & $\begin{array}{c}\text { Gana } \\
5.7\end{array}$ \\
\hline Guatemala & $31.9 \%$ & $\begin{array}{c}\text { Gana } \\
35.2 \mathrm{pp}\end{array}$ & $\begin{array}{c}\text { Gana } \\
6.6 \mathrm{pp}\end{array}$ & $\$ 43,507$ & $\begin{array}{c}8.5 \\
\text { Menos }\end{array}$ & $\begin{array}{c}\text { Gana } \\
63.6 \mathrm{pp}\end{array}$ & $\begin{array}{c}\text { Baja } \\
34.7 \mathrm{pm}\end{array}$ & $\begin{array}{l}\text { Baja } \\
97 \mathrm{pc}\end{array}$ & $\begin{array}{c}\text { Gana } \\
6.7\end{array}$ \\
\hline Honduras & --- & & & & & & & & \\
\hline Nicaragua & $28.9 \%$ & $\begin{array}{c}\text { Gana } \\
30.4 \mathrm{pp}\end{array}$ & $\begin{array}{c}\text { Gana } \\
5.7 \mathrm{pp}\end{array}$ & $\$ 45,237$ & $\begin{array}{c}8.3 \\
\text { Menos }\end{array}$ & $\begin{array}{c}\text { Gana } \\
42.6 \mathrm{pp}\end{array}$ & $\begin{array}{c}\text { Baja } \\
20.7 \mathrm{pm}\end{array}$ & $\begin{array}{c}\text { Baja } \\
87 \mathrm{pc}\end{array}$ & $\begin{array}{c}\text { Gana } \\
3.9\end{array}$ \\
\hline Panamá & ----- & & & & & & & & \\
\hline
\end{tabular}

Nueva York

\begin{tabular}{|c|c|c|c|c|c|c|c|c|c|}
\hline & 3 & $\stackrel{d l}{\square}$ & बाल & (5) & $\frac{8}{4} \frac{8}{4}$ & 11 & $\frac{\circledast}{\pi}$ & $\stackrel{0}{\rho}$ & \\
\hline Belice & -.-- & & & & & & & & \\
\hline Costa Rica & -.-- & & & & & & & & \\
\hline El Salvador & ---- & & & & & & & & \\
\hline Guatemala & --- & & & & & & & & \\
\hline Honduras & ---- & & & & & & & & \\
\hline Nicaragua & 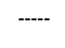 & & & & & & & & \\
\hline Panamá & $17 \%$ & $\begin{array}{c}\text { Gana } \\
2.4 p p\end{array}$ & & $\$ 45,749$ & $\begin{array}{c}11.6 \\
\text { Menos }\end{array}$ & & $\begin{array}{c}\text { Baja } \\
17.2 \text { pm }\end{array}$ & $\begin{array}{c}\text { Baja } \\
43 p c\end{array}$ & $\begin{array}{c}\text { Gana } \\
1.6\end{array}$ \\
\hline
\end{tabular}

Nueva Jersey

\begin{tabular}{|c|c|c|c|c|c|c|c|c|c|}
\hline & 8 & dI & 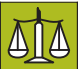 & (5) & $\stackrel{8}{\circ}$ & DI & $\frac{\sigma}{\pi}$ & $\stackrel{\circ}{?}$ & \\
\hline Belice & ---- & & & & & & & & \\
\hline Costa Rica & $15.8 \%$ & $\begin{array}{c}\text { Gana } \\
11.4 \mathrm{pp}\end{array}$ & $\begin{array}{c}\text { Gana } \\
3.9 \mathrm{pp}\end{array}$ & $\$ 42,154$ & $\begin{array}{c}6.4 \\
\text { Menos }\end{array}$ & $\begin{array}{c}\text { Gana } \\
31.7 \mathrm{pp}\end{array}$ & $\begin{array}{c}\text { Baja } \\
5.8 \mathrm{pp}\end{array}$ & $\begin{array}{c}\text { Baja } \\
20 \mathrm{pc}\end{array}$ & $\begin{array}{c}\text { Pierde } \\
1.8\end{array}$ \\
\hline El Salvador & ---- & & & & & & & & \\
\hline Guatemala & ---- & & & & & & & & \\
\hline Honduras & ----- & & & & & & & & \\
\hline Nicaragua & ---- & & & & & & & & \\
\hline Panamá & ---- & & & & & & & & \\
\hline
\end{tabular}

\section{Indicadores}

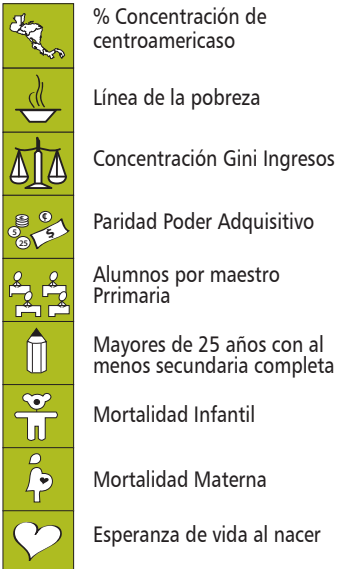

$\left(^{*}\right)$ La primer columna en cada cuadro significa el porcentaje de personas de cada nacionalidad centroamericana que vive en cada uno de los estados de EUA. Por ejemplo: $31.9 \%$ de los emigrantes guatemaltecos que viven en los EUA fueron registrados en California, así como 15.8\% de los costarricenses lo fueron en Nueva Jersey y $17 \%$ de los panameños en Nueva York.

Fuente: Cuadro E del Anexo, basado a su vez en los Cuadros 6 y 7

23. Ver Cuadro No.6. 
socioeconómicos entre los respectivos países de origen de los emigrantes centroamericanos con respecto a los otros tres estados de EUA donde mostraron una concentración Alta: California, Nueva Jersey y Nueva York; dado que Florida ya se presentó en el Cuadro No.8.

Por otra parte, el Cuadro F del Anexo presenta las modificaciones de los indicadores socioeconómicos de los países de origen de los emigrantes centroamericanos al compararlos con los estados donde ellos tienen una "concentración Media" al migrar hacia EUA como se indicó en el Cuadro No.6, observándose nuevamente una mejoría en sus condiciones de vida, exceptuando nuevamente el Índice de Concentración de Gini de los salvadoreños con relación al de Texas, que presenta un valor similar.

Los Cuadros $\mathrm{G}$ en el Anexo, por su parte, muestran los cambios experimentados por los migrantes al desplazarse desde el ambiente prevaleciente en los países centroamericanos hacia aquellos estados de EUA que tienen una "concentración Baja" de migrantes de dichos países. ${ }^{24}$ Se observa un avance en todos los indicadores, exceptuando la esperanza de vida al nacer de los costarricenses en Texas que perderían 2.6 años, y de los panameños en Georgia que perderían 0.8 años-; así como también una mayor concentración del ingreso que encontrarían los salvadoreños en Nueva York, en tres pp del Índice de Gini.

Al interpretar los Cuadros E, F y G del Anexo no debe excluirse que entre las causas de las excepciones mencionadas se deban a diferencias en la calidad de la información o a las diferencias conceptuales que ya fueron mencionadas.

\section{Conclusiones}

El artículo analiza la distribución de los centroamericanos en los EUA y su impacto cuantitativo en los 50 estados de esa unión además del Distrito de Columbia, utilizando especialmente los resultados del Censo de ese país efectuado en 2010.

Para enmarcar dicha migración inicia analizando la presencia latina en los Estados Unidos, observándose que los estados donde la presencia latina era porcentualmente más significativa se encuentran en 5 estados del sur-occidente y sur-centro del país: California, Nevada, Arizona, Nuevo México y Texas. También se constata que los estados con presencia "Media" de hispanos son 12 , ubicados tanto en las zonas noroccidental y central, cercanas a las anteriores: Washington, Oregón, Idaho, Utah, Colorado y Kansas; como también en algunos de la región nororiental (Nueva York, Connecticut, Rhode Island y Nueva Jersey), así como en Illinois al centro y Florida al suroriente. En el caso de los restantes 33 estados y en el Distrito de Columbia la presencia latina en 2010 constituyó menos de 10\% de su respectiva población (Cuadro No.2 y Mapa No.1).

A pesar que en 2010 la presencia latina fue "Baja" en 34 divisiones territoriales - "Alta" sólo en 5 y "Media" en 12-, debe agregarse que entre los años 2000 y 2010 el porcentaje de población latina se había incrementado en todas las divisiones geográficas analizadas: 48 estados tuvieron un crecimiento superior a 25\%, y sólo dos (Nuevo México y Nueva York) así como el Distrito de Columbia tuvieron un incremento intermedio (Mapa No.2 y parte "b" del Cuadro No.2) 25

En lo correspondiente a la inmigración de centroamericanos en los EUA se observa que es mayoritariamente reciente, exceptuando a los panameños.

Del total de centroamericanos que vivían en Estados Unidos en 2009, la mayoría procede del triángulo norte: El Salvador (41.9\%), Guatemala (26.0\%) y Honduras (15.1\%) concentrando así a más de las cuatro quintas partes (83\%) del total de inmigrantes centroamericanos en EUA, ya sea al focalizar en las nuevas generaciones nacidas en EUA (81.1\%) o de la primera generación de

24. Según el Cuadro No.5.

25. Sin embargo, en el Cuadro A del Anexo puede observarse que los porcentajes de cambio entre 2000 y 2010 de esas tres regiones son cercanos al límite que separa los de crecimiento alto con los intermedios: Nuevo México, 24.6\%; DC, 21.8\%; Nueva York, 19.2\%. 
inmigrantes nacidos en su respectivo país de ascendencia (84.1\%). (Cuadro No.4).

La población con ascendencia de los tres países centroamericanos está entre la más joven y con menor nivel de instrucción con relación a la del resto de naciones latinas viviendo en los EUA, como lo indican los porcentajes de quienes tienen diploma universitario o de secundaria ${ }^{26}$; así como también con menor adaptación a su nuevo medio, pues ocupa los últimos lugares en cuanto al dominio del idioma inglés o contar con la ciudadanía (Cuadro No.5).

A pesar de lo anterior, los originarios de esos tres países centroamericanos no ocupan los últimos lugares en cuanto a condiciones económicas y de vida, al compararlos con la situación de las diez comunidades hispanas más numerosas viviendo en los EUA, tanto al usar como indicador al ingreso promedio del hogar ${ }^{27} \mathrm{o}$ al porcentaje de hogares viviendo en condiciones de pobreza. Pero en indicadores sociales destacan por no contar con seguro de salud o por no ser propietarios de la vivienda donde habitan. ${ }^{28}$

El censo de EUA hecho en 2010 muestra que los inmigrantes centroamericanos más numerosos en la mayor parte de estados fueron los de Guatemala y El Salvador (son mayoría en 27 y 22 unidades territoriales, respectivamente), mientras que los de Honduras lo son en Luisiana y los de Nicaragua en Florida (Mapa No.4 y Cuadro C del anexo).

Por otra parte, los emigrantes de cada país centroamericano están muy concentrados: ${ }^{29}$ en sólo siete estados habita $72.9 \%$ del total de emigrados centroamericanos ${ }^{30}$.
$\mathrm{Al}$ analizar la situación de cada nacionalidad se constata que en sólo cinco estados vive $65.6 \%$ de beliceños ${ }^{31}$, $64.7 \%$ de costarricenses ${ }^{32}, 72.5 \%$ de salvadoreños ${ }^{33}$ y $58 \%$ de guatemaltecos ${ }^{34}$; por su parte, $74.1 \%$ de hondureños se concentra en ocho estados ${ }^{35}$; mientras que $73.4 \%$ de nicaragüenses lo hace en sólo tres estados ${ }^{36}$; y seis son los estados donde reside $63.1 \%$ de panameños $^{37}$. Si se toma en cuenta que los Estados Unidos están formados por 50 estados y el Distrito de Columbia, se constata que los centroamericanos están concentrados principalmente en pocos territorios de dicha unión. ${ }^{38}$ (Cuadro No.6, y Cuadro D y Mapas A del anexo).

Para los países CA y los diez estados de los EUA hacia donde más emigran los centroamericanos (Cuadro No.6 y Mapas A del Anexo) se presenta en el Cuadro No.7 algunos indicadores sociales y económicos, para comparar las condiciones promedio que estos emigrantes dejan atrás en sus países de origen y las que encuentran en los estados de destino, con las salvedades indicadas en el texto.

Es necesario ser prudente al compararlos y especialmente al sacar conclusiones, pues no sólo los conceptos de esos indicadores pueden ser diferentes sino que también la calidad en su obtención puede variar, tanto entre los países centroamericanos entre sí como también entre éstos y los estados de destino; por lo que las conclusiones que se derivan de esas comparaciones deben considerarse solamente como aproximaciones de lo que puede significar el cambio de vida de los emigrantes centroamericanos al llegar a los estados de la unión norteamericana, o al regresar a sus respectivos países de origen.

26. La situación real podría ser aún peor de la sugerida por este cuadro, pues él no muestra la población que no tiene ni siquiera diploma secundario.

27. Excepto los inmigrantes de ascendencia hondureña, que quedan en el penúltimo lugar.

28. En este último caso se exceptúa a los salvadoreños, que ocupan una posición intermedia.

29. Se ha considerado que un estado tiene concentración "Alta” de una nacionalidad centroamericana dada si concentra $15 \%$ ó más de los emigrantes de esa nacionalidad. Será "Medio" si concentra entre 10 y 14.9\%, "Baja” entre 4 y 9.9\% y "Muy Baja” si es inferior a 4\%.

30. El conjunto de centroamericanos se concentran en California, Florida, Texas, Nueva York, Virginia, Maryland y Nueva Jersey.

31. $65.6 \%$ de beliceños viven en California, Nueva York, Texas, Florida y Virginia.

32. $64.7 \%$ de costarricenses están concentrados en California, Florida, Nueva Jersey, Nueva York y Texas.

33. $72.5 \%$ de salvadoreños habitan en California, Texas, Nueva York, Maryland y Virginia.

34. $58 \%$ de guatemaltecos viven en California, Florida, Nueva York, Texas y Nueva Jersey.

35. $74.1 \%$ de hondureños residen en Florida, Texas, California, Nueva York, Nueva Jersey, Carolina del Norte, Luisiana y Virginia.

36. $73.4 \%$ de nicaragüenses se concentran en Florida, California y Texas.

37. $63.1 \%$ de panameños habitan en Florida, Nueva York, California, Texas, Georgia y Virginia.

38. La columna de "Diferencia" en el Cuadro 6 indica el porcentaje de cada una de las nacionalidades que vive en el resto de los estados de la unión norteamericana; es decir, los que no están mencionados en este cuadro para cada nacionalidad centroamericana. 
Quienes salieron de los países centroamericanos y se concentraron en los estados de concentración "Alta"39 (California, Florida, Nueva Jersey y Nueva York) logran ambientes donde prevalecen mejores condiciones socioeconómicas, exceptuando el caso de la esperanza de vida al nacer de los costarricenses en California -donde perderían 1.4 años- y en Florida y Nueva Jersey, donde perderían 1.8 años. Otra excepción se observa en el caso de los salvadoreños en California, pues según las estadísticas de dicho país tiene una concentración del ingreso menor que el estado mencionado en 0.2 puntos porcentuales (Cuadros No.8 y No.9 del texto, basados en el Cuadro E del anexo)

En el caso de los emigrantes centroamericanos que se instalaron en los estados donde tienen una "concentración Media" al migrar hacia EUA, también se observa una mejoría en sus condiciones de vida, exceptuando nuevamente el Índice de Concentración de Gini de los salvadoreños con relación al de Texas, que presenta un valor similar. (Cuadro F del anexo)

Los cambios experimentados por los CA que inmigraron hacia estados donde tienen una "concentración Baja"40 muestran también un avance en todos los indicadores, exceptuando la esperanza de vida al nacer de los costarricenses en Texas -donde perderían 2.6 años-, y de los panameños en Georgia -donde perderían 0.8 años-; así como también una mayor concentración del ingreso que encontrarían los salvadoreños en Nueva York, en tres puntos porcentuales del Índice de Gini (Cuadros G del anexo)

Al interpretar los Cuadros E, F y G del anexo no debe excluirse que entre las causas de las excepciones mencionadas se deban a diferencias en la calidad de la información o a las diferencias conceptuales en la obtención de los indicadores.

\section{Bibliografía}

- Abstract, T. S. (08 de diciembre de 2009). U.S. Census Bureau. Recuperado el 20 de noviembre de 2011, de http://www.census.gov/compendia/statab/cats/ population.html

- American Community Survey Briefs. Poverty. (2010). Pobreza 2009- 2010. Recuperado el 14 de Noviembre de 2011, de http://www.census.gov/prod/2011pubs/ acsbr10-01.pdf

- Anuales, C.d. (12 de septiembre de 2011). Index Mundi. Recuperado el 5 de diciembre de 2011, de http:// www.indexmundi.com/g/g.aspx?c $=b h \& v=67 \& l=e s$

- Change, P. D. (22 de diciembre de 2010). United States Census Bureau. Recuperado el 25 de noviembre de 2011, de http://www.census.gov/prod/cen2010/ briefs/c2010br-01.pdf

- Estado de la Región (2011), Estado de la Región en Desarrollo Humano Sostenible, http://www.estadonacion.or.cr/index.php/biblioteca-virtual/centroamerica

- Foundation, H. J. (20 de 12 de 2010). Kaiser State Health Facts. Recuperado el 18 de 11 de 2011, de State Health Facts.org:

http://www.statehealthfacts.org/comparemaptable. jsp? ind $=37$ \& cat $=2$

- Foundation, H. J. (15 de diciembre de 2009). StateHealthFacts.org . Recuperado el 28 de noviembre de 2011, de

http://www.statehealthfacts.org/comparetable.jsp?in $\mathrm{d}=502 \&$ cat $=11 \&$ sub $=118 \& \mathrm{yr}=218 \&$ typ $=2 \&$ sor $\mathrm{t}=\mathrm{a}$

- Index Mundi. (09 de Noviembre de 2011). Index Mundi. Recuperado el 1 de Enero de 2011, de Index Mundi: http://www.indexmundi.com/
39. Ver Cuadro No.6.

40. Según el Cuadro 5. 
- Leduc, T. (04 de 11 de 2011). World Life Expectancy. Recuperado el 06 de 2011, de World Life Expectancy: http://www.worldlifeexpectancy.com/usa/northcarolina-life-expectancy

- Oficina de Censos E.E.U.U. (2011). Anuario Estadístico de los Estados Unidos. Recuperado el 14 de 11 de 2011, de 594 - tasa de participación en la fuerza laboral: 2010: http://www.census.gov/compendia/ statab/cats/labor_force_employment_earnings.html

- Oficina de Censos E.E.U.U. (2011). Resumen Anuario Estadístico E.E.U.U. Recuperado el 13 de 11 de 2011, de 233 - Nivel de Educación por el Estado: http://www.census.gov/compendia/statab/cats/education.html

- Oficina de Censos de los estados Unidos. «Anuario Estadístico de los Estados Unidos 2012.» Vers. Electrónica. 17 - Las tasas de dependencia de edad por estado. 2011. http://www.census.gov/compendia/ statab/ (último acceso: 27 de 11 de 12).

- Pew Hispanic Center Tabulations of 2009 American Community Survey, 2009 Hispanic resident population; citado en http://pewhispanic.org/files/factsheets/hispanics2009/ Table\%207.pdf

- Pew Hispanic Center, Data/ Resources: Country of Origin Profiles. http://pewhispanic.org/data/

- PNUD. (12 de diciembre de 2009). Indicadores Internacionales sobre Desarrollo Humano. Recuperado el 30 de noviembre de 2011, de http://hdrstats.undp.org/es/indicadores/38006.html

- Resumen Anuario Estadístico E.E.U.U. Recuperado el 14 de noviembre de 2011, de 709 - Los individuos y las familias por debajo del nivel de la pobreza: http:// www.census.gov/compendia/statab/cats/income_expenditures_poverty_wealth.html

- Rickety. (12 de diciembre de 2006). Rickety - United States Total Fertility Rate Increases. Recuperado el 15 de diciembre de 2011, de http://www.rickety. us/2009/01/united-states-fertility/
- Sondik, E. J. (09 de Noviembre de 2011). Centers For Disease control and Prevention. Recuperado el 13 de Julio de 2009, de http://www.cdc.gov/nchs/data/databriefs/db64.htm

- State, C. S. (19 de octubre de 2011). U.S. Government Spending. Recuperado el 30 de Noviembre de 2011, de http://www.usgovernmentspending.com/ compare_state_spending_2011p20a

- Statistics, U.S. (30 de diciembre de 2005). InfoPlease. Recuperado el 23 de noviembre de 2011, de http:// www.infoplease.com/ipa/A0005128.html

- United States Government. (01 de 01 de 2010). U.S Census Bureau. Recuperado el 16 de 11 de 2011, de U.S Census Bureau:

http://factfinder2.census.gov/faces/tableservices/ jsf/pages/productview.xhtml?pid $=$ ACS_10_1YR B19083\&prodType $=$ table

- U.S. Census Bureau, http://2010.census. gov/2010census/data/ recuperado el 19 de mayo de 2011

- U.S. Census Bureau, American Fact Finder. http://factfinder2.census.gov/faces/tableservices/ jsf/pages/productview.xhtml?pid=DEC_10_SF1_ QTP10\&prodType =table, consultado el 5 de septiembre de 2011

- U.S. Census Bureau (1 de diciembre de 2011). Estimaciones de la población 2009. Recuperado el 10 de 12 de 2011, de http://factfinder.census.gov/ servlet/GCTTable?-ds_name $=$ PEP_2009_EST\&$\mathrm{mt}$ _name $=$ PEP_2009_EST_GCTT2R_U40SA\&format $=U S-40|U-40 S a| U-40 S b|U-40 S c| U$ 40Sd|U-40Se |U-40Sf|U-40Sg|U-40Sh |US-40S\&CONTEXT $=$ gct\&-geo_id $=$

- U.S. Department of Homeland Security (2010), Yearbook of Immigration Statistics, http://1.usa.gov/rk4SOy

- World Life Expectancy. (22 de octubre de 2011). Recuperado el 07 de diciembre de 2011, de http:// www.worldlifeexpectancy.com/usa/north-carolinachild-death-rate 


\section{Cuadro A}

2010: Población por Estado, y Porcentaje de Ella que fue Calificada Como de Origen Latino o "Hispánico", así como la Variación Porcentual de Ésta entre 2000 y 2010

\begin{tabular}{|c|c|c|c|}
\hline \multirow[b]{2}{*}{ Estado } & \multirow[b]{2}{*}{ Población } & \multicolumn{2}{|c|}{ Porcentaje } \\
\hline & & Origen Latino & Cambio 2000-10 \\
\hline Total & $308,745,538$ & 16.3 & 43.0 \\
\hline Alabama & $4,779,736$ & 3.9 & 144.8 \\
\hline Alaska & 710,231 & 5.5 & 51.8 \\
\hline Arizona & $6,392,017$ & 29.6 & 46.3 \\
\hline Arkansas & $2,915,918$ & 6.4 & 114.2 \\
\hline California & $37,253,956$ & 37.6 & 27.8 \\
\hline Colorado & $5,029,196$ & 20.7 & 41.2 \\
\hline Connecticut & $3,574,097$ & 13.4 & 49.6 \\
\hline Delaware & 897,934 & 8.2 & 96.4 \\
\hline Distrito de Columbia & 601,723 & 9.1 & 21.8 \\
\hline Florida & $18,801,310$ & 22.5 & 57.4 \\
\hline Georgia & $9,687,653$ & 8.8 & 96.1 \\
\hline Hawaii & $1,360,301$ & 8.9 & 37.8 \\
\hline Idaho & $1,567,582$ & 11.2 & 73.0 \\
\hline Illinois & $12,830,632$ & 15.8 & 32.5 \\
\hline Indiana & $6,483,802$ & 6.0 & 81.7 \\
\hline lowa & $3,046,355$ & 5.0 & 83.7 \\
\hline Kansas & $2,853,118$ & 10.5 & 59.4 \\
\hline Kentucky & $4,339,367$ & 3.1 & 121.6 \\
\hline Louissiana & $4,533,372$ & 4.2 & 78.7 \\
\hline Maine & $1,328,361$ & 1.3 & 80.9 \\
\hline Maryland & $5,773,552$ & 8.2 & 106.5 \\
\hline Massachusetts & $6,547,629$ & 9.6 & 46.4 \\
\hline Michigan & $9,883,640$ & 4.4 & 34.7 \\
\hline Minnesota & $5,303,925$ & 4.7 & 74.5 \\
\hline Mississippi & $2,967,297$ & 2.7 & 105.9 \\
\hline Missouri & $5,988,927$ & 3.5 & 79.2 \\
\hline Montana & 989,415 & 2.9 & 58.0 \\
\hline Nebraska & $1,826,341$ & 9.2 & 77.3 \\
\hline Nevada & $2,700,551$ & 26.5 & 81.9 \\
\hline New Hampshire & $1,316,470$ & 2.8 & 79.1 \\
\hline New Jersey & $8,791,894$ & 17.7 & 39.2 \\
\hline New Mexico & $2,059,179$ & 46.3 & 24.6 \\
\hline New York & $19,378,102$ & 17.6 & 19.2 \\
\hline North Carolina & $9,535,483$ & 8.4 & 111.1 \\
\hline North Dakota & 672,591 & 2.0 & 73.0 \\
\hline Ohio & $11,536,504$ & 3.1 & 63.4 \\
\hline Oklahoma & $3,751,351$ & 8.9 & 85.2 \\
\hline Oregón & $3,831,074$ & 11.7 & 63.5 \\
\hline Pennsylvania & $12,702,379$ & 5.7 & 82.6 \\
\hline Rhode Island & $1,052,567$ & 12.4 & 43.9 \\
\hline South Carolina & $4,625,364$ & 5.1 & 147.9 \\
\hline South Dakota & 814,180 & 2.7 & 102.9 \\
\hline Tennessee & $6,346,105$ & 4.6 & 134.2 \\
\hline Texas & $25,145,561$ & 37.6 & 41.8 \\
\hline Utah & $2,763,885$ & 13.0 & 77.8 \\
\hline Vermont & 625,741 & 1.5 & 67.3 \\
\hline Virginia & $8,001,024$ & 7.9 & 91.7 \\
\hline Washington & $6,724,540$ & 11.2 & 71.2 \\
\hline West Virginia & $1,852,994$ & 1.2 & 81.4 \\
\hline Wisconsin & $5,686,986$ & 5.9 & 74.2 \\
\hline Wyoming & 563,626 & 8.9 & 58.6 \\
\hline
\end{tabular}

(*) La población de Puerto Rico en 2010 fue de 3,725,789. Si se agrega a la indicada en el cuadro, la población total del país llega a 312,471,327. En Puerto Rico, 99\% era de origen hispánico, la que entre 2000 y 2010 tuvo una variación de -2\%

Fuente: USA Census Bureau, http//2010.census.gov/2010census/data/ recuperado el 19 de mayo de 2011 


\section{Cuadro B}

Censo 2010: Población Total de los Estados Unidos por Estado y Origen Latino o Centroamericano de sus Inmigrantes

\begin{tabular}{|c|c|c|c|c|c|c|c|c|c|c|}
\hline Estado & $\begin{array}{c}\text { Población } \\
\text { Total }\end{array}$ & $\begin{array}{l}\text { Población } \\
\text { Latina }\end{array}$ & $\begin{array}{c}\text { Población } \\
\text { de CA }\end{array}$ & Belice & $\begin{array}{l}\text { Costa } \\
\text { Rica }\end{array}$ & $\begin{array}{c}\text { EI } \\
\text { Salvador }\end{array}$ & Guatemala & Honduras & Nicaragua & Panamá \\
\hline Alabama & $4,779,736$ & 185,602 & 22,800 & 126 & 504 & 2,419 & 14,282 & 3,280 & 739 & 1,450 \\
\hline Alaska & 710,231 & 39,249 & 2,509 & 29 & 140 & 938 & 508 & 272 & 176 & 446 \\
\hline Arizona & $6,392,017$ & $1,895,149$ & 36,642 & 386 & 1,573 & 12,225 & 13,426 & 3,968 & 2,813 & 2,251 \\
\hline Arkansas & $2,915,918$ & 186,050 & 23,216 & 105 & 333 & 14,980 & 4,533 & 2,076 & 704 & 485 \\
\hline California & $37,253,956$ & $14,013,719$ & $1,132,520$ & 12,005 & 22,469 & 573,956 & 332,737 & 72,795 & 100,790 & 17,768 \\
\hline Colorado & $5,029,196$ & $1,038,687$ & 29,386 & 331 & 1,104 & 12,329 & 7,488 & 4,356 & 1,364 & 2,414 \\
\hline Connecticut & $3,574,097$ & 479,087 & 35,023 & 234 & 2,767 & 6,223 & 16,715 & 6,242 & 1,538 & 1,304 \\
\hline Delaware & 897,934 & 73,221 & 8,112 & 35 & 243 & 1,231 & 5,202 & 675 & 225 & 501 \\
\hline Distrito de Columbia & 601,723 & 54,749 & 23,354 & 110 & 258 & 16,611 & 2,635 & 2,139 & 859 & 742 \\
\hline Florida & $18,801,310$ & $4,223,806$ & 432,665 & 1,692 & 20,761 & 55,144 & 83,882 & 107,302 & 135,143 & 28,741 \\
\hline Georgia & $9,687,653$ & 853,689 & 106,987 & 850 & 3,114 & 32,107 & 36,874 & 20,577 & 4,787 & 8,678 \\
\hline Hawaii & $1,360,301$ & 120,842 & 2,962 & 54 & 289 & 801 & 565 & 390 & 336 & 527 \\
\hline Idaho & $1,567,582$ & 175,901 & 3,494 & 31 & 230 & 1,159 & 1,168 & 461 & 222 & 223 \\
\hline Illinois & $12,830,632$ & $2,027,578$ & 70,000 & 644 & 1,874 & 14,217 & 35,321 & 12,023 & 3,078 & 2,843 \\
\hline Indiana & $6,483,802$ & 389,707 & 22,093 & 173 & 592 & 7,401 & 5,933 & 5,345 & 1,431 & 1,218 \\
\hline lowa & $3,046,355$ & 151,544 & 13,289 & 92 & 255 & 5,601 & 4,917 & 1,539 & 472 & 413 \\
\hline Kansas & $2,853,118$ & 300,042 & 15,293 & 148 & 385 & 5,108 & 5,538 & 2,689 & 537 & 888 \\
\hline Kentuky & $4,339,367$ & 132,836 & 11,479 & 87 & 253 & 2,351 & 5,231 & 2,012 & 526 & 1,019 \\
\hline Louisiana & $4,533,372$ & 192,560 & 51,722 & 289 & 1,212 & 5,120 & 6,660 & 30,617 & 6,390 & 1,434 \\
\hline Maine & $1,328,361$ & 16,935 & 1,708 & 18 & 105 & 618 & 457 & 280 & 89 & 141 \\
\hline Maryland & $5,773,552$ & 470,632 & 195,692 & 995 & 2,304 & 123,789 & 34,491 & 20,576 & 8,196 & 5,341 \\
\hline Massachusetts & $6,547,629$ & 627,654 & 96,958 & 1,104 & 2,951 & 43,400 & 32,812 & 12,533 & 1,722 & 2,436 \\
\hline Michigan & $9,883,640$ & 436,358 & 17,785 & 130 & 903 & 3,401 & 8,428 & 2,694 & 870 & 1,359 \\
\hline Minnesota & $5,303,925$ & 250,258 & 19,908 & 132 & 785 & 7,175 & 6,754 & 3,186 & 970 & 906 \\
\hline Mississippi & $2,967,297$ & 81,481 & 8,343 & 56 & 317 & 1,174 & 2,978 & 2,448 & 700 & 670 \\
\hline Missouri & $5,988,927$ & 212,470 & 17,763 & 89 & 587 & 4,628 & 6,610 & 3,657 & 843 & 1,349 \\
\hline Montana & 989,415 & 28,565 & 735 & 4 & 71 & 140 & 200 & 98 & 91 & 131 \\
\hline Nebraska & $1,826,341$ & 167,405 & 17,242 & 152 & 166 & 6,016 & 8,616 & 1,547 & 347 & 398 \\
\hline Nevada & $2,700,551$ & 716,501 & 55,937 & 483 & 1,433 & 30,043 & 13,407 & 4,481 & 4,475 & 1,615 \\
\hline New Hampshire & $1,316,470$ & 36,704 & 2,731 & 38 & 233 & 823 & 743 & 506 & 174 & 214 \\
\hline New Jersey & $8,791,894$ & $1,555,144$ & 176,611 & 1,068 & 19,933 & 56,532 & 48,869 & 36,556 & 8,222 & 5,431 \\
\hline New Mexico & $2,059,179$ & 953,403 & 6,621 & 67 & 342 & 2,051 & 2,386 & 657 & 493 & 625 \\
\hline New York & $19,378,102$ & $3,416,922$ & 353,589 & 2,952 & 11,576 & 152,130 & 73,806 & 71,919 & 13,006 & 28,200 \\
\hline North Carolina & $9,535,483$ & 800,120 & 105,066 & 852 & 4,658 & 37,778 & 20,206 & 30,900 & 4,964 & 5,708 \\
\hline North Dakota & 672,591 & 13,467 & 452 & 1 & 35 & 73 & 134 & 50 & 59 & 100 \\
\hline Ohio & $11,536,504$ & 354,674 & 22,756 & 219 & 1,093 & 5,627 & 8,680 & 3,699 & 1,383 & 2,055 \\
\hline Oklahoma & $3,751,351$ & 332,007 & 15,641 & 177 & 413 & 2,788 & 7,960 & 2,711 & 470 & 1,122 \\
\hline Oregon & $3,831,074$ & 450,062 & 18,190 & 197 & 911 & 5,906 & 7,703 & 1,644 & 1,104 & 725 \\
\hline Pennsylvania & $12,702,379$ & 719,660 & 35,453 & 302 & 3,048 & 7,952 & 11,462 & 7,055 & 2,400 & 3,234 \\
\hline Rhode Island & $1,052,567$ & 130,655 & 23,817 & 132 & 242 & 2,715 & 18,852 & 1,250 & 267 & 359 \\
\hline South Carolina & $4,625,364$ & 235,682 & 26,290 & 136 & 1,943 & 3,830 & 8,883 & 8,091 & 1,303 & 2,104 \\
\hline South Dakota & 814,180 & 22,119 & 2,891 & 51 & 46 & 780 & 1,620 & 221 & 99 & 74 \\
\hline Tennessee & $6,346,105$ & 290,059 & 36,856 & 209 & 1,045 & 8,570 & 14,323 & 9,455 & 1,339 & 1,915 \\
\hline Texas & $25,145,561$ & $9,460,921$ & 420,683 & 2,658 & 6,982 & 222,599 & 66,244 & 88,389 & 19,817 & 13,994 \\
\hline Utah & $2,763,885$ & 358,340 & 20,442 & 131 & 775 & 8,998 & 6,877 & 2,087 & 1,043 & 531 \\
\hline Vermont & 625,741 & 9,208 & 671 & 1 & 73 & 116 & 215 & 109 & 66 & 91 \\
\hline Virginia & $8,001,024$ & 631,825 & 206,568 & 1,431 & 2,630 & 123,800 & 33,556 & 30,583 & 7,388 & 7,180 \\
\hline Washington & $6,724,540$ & 755,790 & 33,661 & 308 & 1,563 & 12,637 & 9,520 & 4,381 & 2,313 & 2,939 \\
\hline West Virginia & $1,852,994$ & 22,286 & 2,081 & 17 & 68 & 893 & 347 & 333 & 162 & 261 \\
\hline Wisconsin & $5,696,986$ & 336,056 & 10,616 & 85 & 779 & 1,867 & 3,037 & 2,402 & 1,624 & 822 \\
\hline Wyoming & 563,626 & 50,231 & 977 & 10 & 52 & 198 & 418 & 145 & 73 & 81 \\
\hline Total & $308,755,538$ & $50,477,612$ & $3,998,280$ & 31,626 & 126,418 & $1,648,968$ & $1,044,209$ & 633,401 & 348,202 & 165,456 \\
\hline
\end{tabular}

Fuente: U.S. Census Bureau. American Fact Finder. http://factfinder2.census.gov/faces/tableservices/jsf/pages/productview.xhtml?pid=DEC_10_SF1_QTP10\&prodType=table Consultado el 05 de Septiembre de 2011. 
Cuadro C

Censo 2010: Distribución Porcentual de los Inmigrantes por País o Región en cada Estado

\begin{tabular}{|c|c|c|c|c|c|c|c|c|c|c|c|}
\hline Estado & Latinos 1/ & CA/PT 2/ & CA/Latinos 3/ & Belice & Costa Rica & El Salvador & Guatemala & Honduras & Nicaragua & Panamá & Total CA \\
\hline Alabama & 3.9 & 0.5 & 12 & 0.6 & 2.2 & 10.6 & 62.6 & 14.4 & 3.2 & 6.4 & 100.0 \\
\hline Alaska & 5.5 & 0.4 & 6 & 1.2 & 5.6 & 37.4 & 20.2 & 10.8 & 7.0 & 17.8 & 100.0 \\
\hline Arizona & 29.6 & 0.6 & 2 & 1.1 & 4.3 & 33.4 & 36.6 & 10.8 & 7.7 & 6.1 & 100.0 \\
\hline Arkansas & 6.4 & 0.8 & 12 & 0.5 & 1.4 & 64.5 & 19.5 & 8.9 & 3.0 & 2.1 & 100.0 \\
\hline California & 37.6 & 3.0 & 8 & 1.1 & 2.0 & 50.7 & 29.4 & 6.4 & 8.9 & 1.6 & 100.0 \\
\hline Colorado & 20.7 & 0.6 & 3 & 1.1 & 3.8 & 42.0 & 25.5 & 14.8 & 4.6 & 8.2 & 100.0 \\
\hline Connecticut & 13.4 & 1.0 & 7 & 0.7 & 7.9 & 17.8 & 47.7 & 17.8 & 4.4 & 3.7 & 100.0 \\
\hline Delaware & 8.2 & 0.9 & 11 & 0.4 & 3.0 & 15.2 & 64.1 & 8.3 & 2.8 & 6.2 & 100.0 \\
\hline Distrito de Columbia & 9.1 & 3.9 & 43 & 0.5 & 1.1 & 71.1 & 11.3 & 9.2 & 3.7 & 3.2 & 100.0 \\
\hline Florida & 22.5 & 2.3 & 10 & 0.4 & 4.8 & 12.7 & 19.4 & 24.8 & 31.2 & 6.6 & 100.0 \\
\hline Georgia & 8.8 & 1.1 & 13 & 0.8 & 2.9 & 30.0 & 34.5 & 19.2 & 4.5 & 8.1 & 100.0 \\
\hline Hawaii & 8.9 & 0.2 & 2 & 1.8 & 9.8 & 27.0 & 19.1 & 13.2 & 11.3 & 17.8 & 100.0 \\
\hline Idaho & 11.2 & 0.2 & 2 & 0.9 & 6.6 & 33.2 & 33.4 & 13.2 & 6.4 & 6.4 & 100.0 \\
\hline Illinois & 15.8 & 0.5 & 3 & 0.9 & 2.7 & 20.3 & 50.5 & 17.2 & 4.4 & 4.1 & 100.0 \\
\hline Indiana & 6.0 & 0.3 & 6 & 0.8 & 2.7 & 33.5 & 26.9 & 24.2 & 6.5 & 5.5 & 100.0 \\
\hline lowa & 5.0 & 0.4 & 9 & 0.7 & 1.9 & 42.1 & 37.0 & 11.6 & 3.6 & 3.1 & 100.0 \\
\hline Kansas & 10.5 & 0.5 & 5 & 1.0 & 2.5 & 33.4 & 36.2 & 17.6 & 3.5 & 5.8 & 100.0 \\
\hline Kentuky & 3.1 & 0.3 & 9 & 0.8 & 2.2 & 20.5 & 45.6 & 17.5 & 4.6 & 8.9 & 100.0 \\
\hline Louisiana & 4.2 & 1.1 & 27 & 0.6 & 2.3 & 9.9 & 12.9 & 59.2 & 12.4 & 2.8 & 100.0 \\
\hline Maine & 1.3 & 0.1 & 10 & 1.1 & 6.1 & 36.2 & 26.8 & 16.4 & 5.2 & 8.3 & 100.0 \\
\hline Maryland & 8.2 & 3.4 & 42 & 0.5 & 1.2 & 63.3 & 17.6 & 10.5 & 4.2 & 2.7 & 100.0 \\
\hline Massachusetts & 9.6 & 1.5 & 15 & 1.1 & 3.0 & 44.8 & 33.8 & 12.9 & 1.8 & 2.5 & 100.0 \\
\hline Michigan & 4.4 & 0.2 & 4 & 0.7 & 5.1 & 19.1 & 47.4 & 15.1 & 4.9 & 7.6 & 100.0 \\
\hline Minnesota & 4.7 & 0.4 & 8 & 0.7 & 3.9 & 36.0 & 33.9 & 16.0 & 4.9 & 4.6 & 100.0 \\
\hline Mississippi & 2.7 & 0.3 & 10 & 0.7 & 3.8 & 14.1 & 35.7 & 29.3 & 8.4 & 8.0 & 100.0 \\
\hline Missouri & 3.5 & 0.3 & 8 & 0.5 & 3.3 & 26.1 & 37.2 & 20.6 & 4.7 & 7.6 & 100.0 \\
\hline Montana & 2.9 & 0.1 & 3 & 0.5 & 9.7 & 19.0 & 27.2 & 13.3 & 12.4 & 17.8 & 100.0 \\
\hline Nebraska & 9.2 & 0.9 & 10 & 0.9 & 1.0 & 34.9 & 50.0 & 9.0 & 2.0 & 2.3 & 100.0 \\
\hline Nevada & 26.5 & 2.1 & 8 & 0.9 & 2.6 & 53.7 & 24.0 & 8.0 & 8.0 & 2.9 & 100.0 \\
\hline New Hampshire & 2.8 & 0.2 & 7 & 1.4 & 8.5 & 30.1 & 27.2 & 18.5 & 6.4 & 7.8 & 100.0 \\
\hline New Jersey & 17.7 & 2.0 & 11 & 0.6 & 11.3 & 32.0 & 27.7 & 20.7 & 4.7 & 3.1 & 100.0 \\
\hline New Mexico & 46.3 & 0.3 & 1 & 1.0 & 5.2 & 31.0 & 36.0 & 9.9 & 7.4 & 9.4 & 100.0 \\
\hline New York & 17.6 & 1.8 & 10 & 0.8 & 3.3 & 43.0 & 20.9 & 20.3 & 3.7 & 8.0 & 100.0 \\
\hline North Carolina & 8.4 & 1.1 & 13 & 0.8 & 4.4 & 36.0 & 19.2 & 29.4 & 4.7 & 5.4 & 100.0 \\
\hline North Dakota & 2.0 & 0.1 & 3 & 0.2 & 7.7 & 16.2 & 29.6 & 11.1 & 13.1 & 22.1 & 100.0 \\
\hline Ohio & 3.1 & 0.2 & 6 & 1.0 & 4.8 & 24.7 & 38.1 & 16.3 & 6.1 & 9.0 & 100.0 \\
\hline Oklahoma & 8.9 & 0.4 & 5 & 1.1 & 2.6 & 17.8 & 50.9 & 17.3 & 3.0 & 7.2 & 100.0 \\
\hline Oregon & 11.7 & 0.5 & 4 & 1.1 & 5.0 & 32.5 & 42.3 & 9.0 & 6.1 & 4.0 & 100.0 \\
\hline Pennsylvania & 5.7 & 0.3 & 5 & 0.9 & 8.6 & 22.4 & 32.3 & 19.9 & 6.8 & 9.1 & 100.0 \\
\hline Rhode Island & 12.4 & 2.3 & 18 & 0.6 & 1.0 & 11.4 & 79.2 & 5.2 & 1.1 & 1.5 & 100.0 \\
\hline South Carolina & 5.1 & 0.6 & 11 & 0.5 & 7.4 & 14.6 & 33.8 & 30.8 & 5.0 & 8.0 & 100.0 \\
\hline South Dakota & 2.7 & 0.4 & 13 & 1.8 & 1.6 & 27.0 & 56.0 & 7.6 & 3.4 & 2.6 & 100.0 \\
\hline Tennessee & 4.6 & 0.6 & 13 & 0.6 & 2.8 & 23.3 & 38.9 & 25.7 & 3.6 & 5.2 & 100.0 \\
\hline Texas & 37.6 & 1.7 & 4 & 0.6 & 1.7 & 52.9 & 15.7 & 21.0 & 4.7 & 3.3 & 100.0 \\
\hline Utah & 13.0 & 0.7 & 6 & 0.6 & 3.8 & 44.0 & 33.6 & 10.2 & 5.1 & 2.6 & 100.0 \\
\hline Vermont & 1.5 & 0.1 & 7 & 0.1 & 10.9 & 17.3 & 32.0 & 16.2 & 9.8 & 13.6 & 100.0 \\
\hline Virginia & 7.9 & 2.6 & 33 & 0.7 & 1.3 & 59.9 & 16.2 & 14.8 & 3.6 & 3.5 & 100.0 \\
\hline Washington & 11.2 & 0.5 & 4 & 0.9 & 4.6 & 37.5 & 28.3 & 13.0 & 6.9 & 8.7 & 100.0 \\
\hline West Virginia & 1.2 & 0.1 & 9 & 0.8 & 3.3 & 42.9 & 16.7 & 16.0 & 7.8 & 12.5 & 100.0 \\
\hline Wisconsin & 5.9 & 0.2 & 3 & 0.8 & 7.3 & 17.6 & 28.6 & 22.6 & 15.3 & 7.7 & 100.0 \\
\hline Wyoming & 8.9 & 0.2 & 2 & 1.0 & 5.3 & 20.3 & 42.8 & 14.8 & 7.5 & 8.3 & 100.0 \\
\hline Total & 16.3 & 1.3 & 8 & 0.8 & 3.2 & 41.2 & 26.1 & 15.8 & 8.7 & 4.1 & 100.0 \\
\hline
\end{tabular}

1/ Población latina viviendo en cada Estado

2/ Porcentaje de Centroamericanos en el conjunto de la población de cada Estado

3/ Porcentaje de Centroamericanos entre los Latinos viviendo en cada Estado

Fuente: Cuadro B del Anexo. 
Cuadro D

Censo 2010: Distribución Porcentual de la Población de cada País o Región de Origen según Estado de Resistencia

\begin{tabular}{|c|c|c|c|c|c|c|c|c|c|c|}
\hline Estado & $\begin{array}{c}\text { Población } \\
\text { Total }\end{array}$ & $\begin{array}{l}\text { Población } \\
\text { Latina }\end{array}$ & $\begin{array}{c}\text { Población } \\
\text { de CA }\end{array}$ & Belice & Costa Rica & El Salvador & Guatemala & Honduras & Nicaragua & Panamá \\
\hline Alabama & 1.5 & 0.4 & 0.6 & 0.4 & 0.4 & 0.1 & 1.4 & 0.5 & 0.2 & 0.9 \\
\hline Alaska & 0.2 & 0.1 & 0.1 & 0.1 & 0.1 & 0.1 & 0.0 & 0.0 & 0.1 & 0.3 \\
\hline Arizona & 2.1 & 3.8 & 0.9 & 1.2 & 1.2 & 0.7 & 1.3 & 0.6 & 0.8 & 1.4 \\
\hline Arkansas & 0.9 & 0.4 & 0.6 & 0.3 & 0.3 & 0.9 & 0.4 & 0.3 & 0.2 & 0.3 \\
\hline California & 12.1 & 27.8 & 28.3 & 38.0 & 17.8 & 34.8 & 31.9 & 11.5 & 28.9 & 10.7 \\
\hline Colorado & 1.6 & 2.1 & 0.7 & 1.0 & 0.9 & 0.7 & 0.7 & 0.7 & 0.4 & 1.5 \\
\hline Connecticut & 1.2 & 0.9 & 0.9 & 0.7 & 2.2 & 0.4 & 1.6 & 1.0 & 0.4 & 0.8 \\
\hline Delaware & 0.3 & 0.1 & 0.2 & 0.1 & 0.2 & 0.1 & 0.5 & 0.1 & 0.1 & 0.3 \\
\hline District of Columbia & 0.2 & 0.1 & 0.6 & 0.3 & 0.2 & 1.0 & 0.3 & 0.3 & 0.2 & 0.4 \\
\hline Florida & 6.1 & 8.4 & 10.8 & 5.4 & 16.4 & 3.3 & 8.0 & 16.9 & 38.8 & 17.4 \\
\hline Georgia & 3.1 & 1.7 & 2.7 & 2.7 & 2.5 & 1.9 & 3.5 & 3.2 & 1.4 & 5.2 \\
\hline Hawaii & 0.4 & 0.2 & 0.1 & 0.2 & 0.2 & 0.0 & 0.1 & 0.1 & 0.1 & 0.3 \\
\hline Idaho & 0.5 & 0.3 & 0.1 & 0.1 & 0.2 & 0.1 & 0.1 & 0.1 & 0.1 & 0.1 \\
\hline Illinois & 4.2 & 4.0 & 1.8 & 2.0 & 1.5 & 0.9 & 3.4 & 1.9 & 0.9 & 1.7 \\
\hline Indiana & 2.1 & 0.8 & 0.6 & 0.5 & 0.5 & 0.4 & 0.6 & 0.8 & 0.4 & 0.7 \\
\hline lowa & 1.0 & 0.3 & 0.3 & 0.3 & 0.2 & 0.3 & 0.5 & 0.2 & 0.1 & 0.2 \\
\hline Kansas & 0.9 & 0.6 & 0.4 & 0.5 & 0.3 & 0.3 & 0.5 & 0.4 & 0.2 & 0.5 \\
\hline Kentuky & 1.4 & 0.3 & 0.3 & 0.3 & 0.2 & 0.1 & 0.5 & 0.3 & 0.2 & 0.6 \\
\hline Louisiana & 1.5 & 0.4 & 1.3 & 0.9 & 1.0 & 0.3 & 0.6 & 4.8 & 1.8 & 0.9 \\
\hline Maine & 0.4 & 0.0 & 0.0 & 0.1 & 0.1 & 0.0 & 0.0 & 0.0 & 0.0 & 0.1 \\
\hline Maryland & 1.9 & 0.9 & 4.9 & 3.1 & 1.8 & 7.5 & 3.3 & 3.2 & 2.4 & 3.2 \\
\hline Massachusetts & 2.1 & 1.2 & 2.4 & 3.5 & 2.3 & 2.6 & 3.1 & 2.0 & 0.5 & 1.5 \\
\hline Michigan & 3.2 & 0.9 & 0.4 & 0.4 & 0.7 & 0.2 & 0.8 & 0.4 & 0.2 & 0.8 \\
\hline Minnesota & 1.7 & 0.5 & 0.5 & 0.4 & 0.6 & 0.4 & 0.6 & 0.5 & 0.3 & 0.5 \\
\hline Mississippi & 1.0 & 0.2 & 0.2 & 0.2 & 0.3 & 0.1 & 0.3 & 0.4 & 0.2 & 0.4 \\
\hline Missouri & 1.9 & 0.4 & 0.4 & 0.3 & 0.5 & 0.3 & 0.6 & 0.6 & 0.2 & 0.8 \\
\hline Montana & 0.3 & 0.1 & 0.0 & 0.0 & 0.1 & 0.0 & 0.0 & 0.0 & 0.0 & 0.1 \\
\hline Nebraska & 0.6 & 0.3 & 0.4 & 0.5 & 0.1 & 0.4 & 0.8 & 0.2 & 0.1 & 0.2 \\
\hline Nevada & 0.9 & 1.4 & 1.4 & 1.5 & 1.1 & 1.8 & 1.3 & 0.7 & 1.3 & 1.0 \\
\hline New Hampshire & 0.4 & 0.1 & 0.1 & 0.1 & 0.2 & 0.0 & 0.1 & 0.1 & 0.0 & 0.1 \\
\hline New Jersey & 2.8 & 3.1 & 4.4 & 3.4 & 15.8 & 3.4 & 4.7 & 5.8 & 2.4 & 3.3 \\
\hline New Mexico & 0.7 & 1.9 & 0.2 & 0.2 & 0.3 & 0.1 & 0.2 & 0.1 & 0.1 & 0.4 \\
\hline New York & 6.3 & 6.8 & 8.8 & 9.3 & 9.2 & 9.2 & 7.1 & 11.4 & 3.7 & 17.0 \\
\hline North Carolina & 3.1 & 1.6 & 2.6 & 2.7 & 3.7 & 2.3 & 1.9 & 4.9 & 1.4 & 3.4 \\
\hline North Dakota & 0.2 & 0.0 & 0.0 & 0.0 & 0.0 & 0.0 & 0.0 & 0.0 & 0.0 & 0.1 \\
\hline Ohio & 3.7 & 0.7 & 0.6 & 0.7 & 0.9 & 0.3 & 0.8 & 0.6 & 0.4 & 1.2 \\
\hline Oklahoma & 1.2 & 0.7 & 0.4 & 0.6 & 0.3 & 0.2 & 0.8 & 0.4 & 0.1 & 0.7 \\
\hline Oregon & 1.2 & 0.9 & 0.5 & 0.6 & 0.7 & 0.4 & 0.7 & 0.3 & 0.3 & 0.4 \\
\hline Pennsylvania & 4.1 & 1.4 & 0.9 & 1.0 & 2.4 & 0.5 & 1.1 & 1.1 & 0.7 & 2.0 \\
\hline Rhode Island & 0.3 & 0.3 & 0.6 & 0.4 & 0.2 & 0.2 & 1.8 & 0.2 & 0.1 & 0.2 \\
\hline South Carolina & 1.5 & 0.5 & 0.7 & 0.4 & 1.5 & 0.2 & 0.9 & 1.3 & 0.4 & 1.3 \\
\hline South Dakota & 0.3 & 0.0 & 0.1 & 0.2 & 0.0 & 0.0 & 0.2 & 0.0 & 0.0 & 0.0 \\
\hline Tennessee & 2.1 & 0.6 & 0.9 & 0.7 & 0.8 & 0.5 & 1.4 & 1.5 & 0.4 & 1.2 \\
\hline Texas & 8.1 & 18.7 & 10.5 & 8.4 & 5.5 & 13.5 & 6.3 & 14.0 & 5.7 & 8.5 \\
\hline Utah & 0.9 & 0.7 & 0.5 & 0.4 & 0.6 & 0.5 & 0.7 & 0.3 & 0.3 & 0.3 \\
\hline Vermont & 0.2 & 0.0 & 0.0 & 0.0 & 0.1 & 0.0 & 0.0 & 0.0 & 0.0 & 0.1 \\
\hline Virginia & 2.6 & 1.3 & 5.2 & 4.5 & 2.1 & 7.5 & 3.2 & 4.8 & 2.1 & 4.3 \\
\hline Washington & 2.2 & 1.5 & 0.8 & 1.0 & 1.2 & 0.8 & 0.9 & 0.7 & 0.7 & 1.8 \\
\hline West Virginia & 0.6 & 0.0 & 0.1 & 0.1 & 0.1 & 0.1 & 0.0 & 0.1 & 0.0 & 0.2 \\
\hline Wisconsin & 1.8 & 0.7 & 0.3 & 0.3 & 0.6 & 0.1 & 0.3 & 0.4 & 0.5 & 0.5 \\
\hline Wyoming & 0.2 & 0.1 & 0.0 & 0.0 & 0.0 & 0.0 & 0.0 & 0.0 & 0.0 & 0.0 \\
\hline Total & 100.0 & 100.0 & 100.0 & 100.0 & 100.0 & 100.0 & 100.0 & 100.0 & 100.0 & 100.0 \\
\hline
\end{tabular}

Fuente: Cuadro B del Anexo. 


\section{Mapas A}

Clasificación de los Estados Según la Concentración en Ellos de los Emigrantes de Países Centroamericanos

Centroamérica

El Salvador

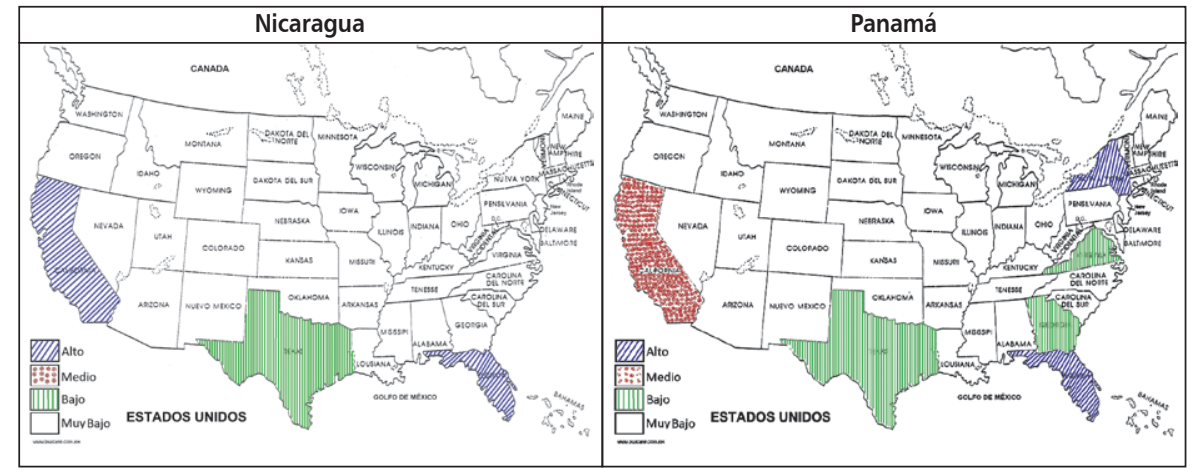

Fuente: Cuadros B y D del Anexo 


\section{Cuadro E}

\section{Cambios en Indicadores de Migrantes Centroamericanos, por País de Origen y Estado de Destino con Concentración Alta}

\begin{tabular}{|c|c|c|c|c|c|c|c|}
\hline \multirow{2}{*}{\begin{tabular}{|l} 
Estado de \\
Destino
\end{tabular}} & \multicolumn{7}{|c|}{ País de Origen } \\
\hline & Belice & Costa Rica & El Salvador & Guatemala & Honduras & Nicaragua & Panamá \\
\hline \multirow{9}{*}{ 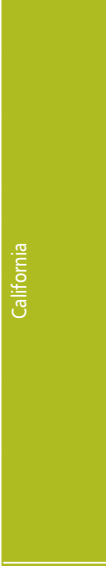 } & Atrae $38 \%$ de beliceños & Atrae $17.8 \%$ de costarricenses & Atrae $34.8 \%$ de salvadoreños & $\begin{array}{l}\text { Atrae } 31.9 \% \text { de guatemal- } \\
\text { tecos }\end{array}$ & & $\begin{array}{l}\text { Atrae } 28.9 \% \text { de nicara- } \\
\text { güenses }\end{array}$ & \\
\hline & $\begin{array}{l}\text { Gana } 17 \mathrm{pp}^{1} \text { en línea de } \\
\text { pobreza }^{2}\end{array}$ & Gana 5.9 pp$^{1}$ en línea de pobreza ${ }^{2}$ & $\begin{array}{l}\text { Gana } 22 \mathrm{pp}^{1} \text { en línea de po- } \\
\text { breza }^{2}\end{array}$ & $\begin{array}{l}\text { Gana } 35.2 \mathrm{pp}^{1} \text { en línea de } \\
\text { pobreza }^{2}\end{array}$ & & $\begin{array}{l}\text { Gana } 30.4 \text { pp}^{1} \text { en línea de } \\
\text { pobreza }^{2}\end{array}$ & \\
\hline & & $\begin{array}{l}\text { Gana } 3.2 \mathrm{pp}^{1} \text { en menor concentra- } \\
\text { ción Gini ingresos }\end{array}$ & $\begin{array}{l}\text { Pierde } 0.2 \mathrm{pp} 1 \text { en menor con- } \\
\text { centración Gini ingresos }\end{array}$ & $\begin{array}{l}\text { Gana } 6.6 \mathrm{pp}^{1} \text { en menor con- } \\
\text { centración Gini ingresos }\end{array}$ & & $\begin{array}{l}\text { Gana } 5.7 \mathrm{pp}^{1} \text { en menor } \\
\text { concentración } \text { Gini in- } \\
\text { gresos }\end{array}$ & \\
\hline & Gana $\$ 42,325 \mathrm{PPA}^{3}$ & Gana $\$ 38,678 P^{P P A^{3}}$ & Gana $\$ 42,943$ PPA $^{3}$ & Gana $\$ 43,507 \mathrm{PPA}^{3}$ & & Gana $\$ 45,237$ PPA $^{3}$ & \\
\hline & $\begin{array}{l}1.7 \text { alumnos menos por } \\
\text { maestro, Primaria }\end{array}$ & $\begin{array}{l}2.5 \text { alumnos más por maestro, } \\
\text { Primaria }\end{array}$ & $\begin{array}{l}11.7 \text { alumnos menos por } \\
\text { maestro, Primaria }\end{array}$ & $\begin{array}{l}8.5 \text { alumnos menos por } \\
\text { maestro, Primaria }\end{array}$ & & $\begin{array}{l}8.3 \text { alumnos menos por } \\
\text { maestro, Primaria }\end{array}$ & \\
\hline & $\begin{array}{l}\text { Gana aprox. } 47.6 \mathrm{pp}^{1} \text { de } \\
\text { mayores de } 25 \text { años con al } \\
\text { menos secundaria completa }\end{array}$ & $\begin{array}{l}\text { Gana aprox } 21.6 \mathrm{pp}^{1} \text { de mayores } \\
\text { de } 25 \text { años con al menos secunda- } \\
\text { ria completa }\end{array}$ & $\begin{array}{l}\text { Gana aprox } 37.6 \mathrm{pp}^{1} \text { de mayo- } \\
\text { res de } 25 \text { años con al menos } \\
\text { secundaria completa }\end{array}$ & $\begin{array}{l}\text { Gana aprox } 63.6 \mathrm{pp}^{1} \text { de ma- } \\
\text { yores de } 25 \text { años con al me- } \\
\text { nos secundaria completa }\end{array}$ & & $\begin{array}{l}\text { Gana aprox } 42.6 \mathrm{pp}^{1} \text { de } \\
\text { mayores de } 25 \text { años con } \\
\text { al menos secundaria com- } \\
\text { pleta }\end{array}$ & \\
\hline & $\begin{array}{l}\text { Baja en } 12.7 \mathrm{pm}^{4} \text { la morta- } \\
\text { lidad de menores de } 5 \text { años }\end{array}$ & $\begin{array}{l}\text { Baja en } 5.7 \mathrm{pm}^{4} \text { la mortalidad de } \\
\text { menores de } 5 \text { años }\end{array}$ & $\begin{array}{l}\text { Baja en } 11.7 \mathrm{pm}^{4} \text { la mortalidad } \\
\text { de menores de } 5 \text { años }\end{array}$ & $\begin{array}{l}\text { Baja en } 34.7 \text { pm }^{4} \text { la morta- } \\
\text { lidad de menores de } 5 \text { años }\end{array}$ & & $\begin{array}{l}\text { Baja en } 20.7 \mathrm{pm}^{4} \text { la mor- } \\
\text { talidad de menores de } 5 \\
\text { años }\end{array}$ & \\
\hline & $\begin{array}{l}\text { Baja en } 81 \mathrm{pc}^{5} \text { la mortalidad } \\
\text { materna }\end{array}$ & $\begin{array}{l}\text { Baja en } 31 p^{5} c^{5} \text { la mortalidad ma- } \\
\text { terna }\end{array}$ & $\begin{array}{l}\text { Baja en } 97 \mathrm{pc}^{5} \text { la mortalidad } \\
\text { materna }\end{array}$ & $\begin{array}{l}\text { Baja en } 97 p^{5} c^{5} \text { la mortalidad } \\
\text { materna }\end{array}$ & & $\begin{array}{l}\text { Baja en } 87 p^{5} \text { la mortali- } \\
\text { dad materna }\end{array}$ & \\
\hline & $\begin{array}{l}\text { Gana } 1.8 \text { años de esperanza } \\
\text { de vida }\end{array}$ & $\begin{array}{l}\text { Pierde } 1.4 \text { años de esperanza de } \\
\text { vida }\end{array}$ & $\begin{array}{l}\text { Gana } 5.7 \text { años de esperanza } \\
\text { de vida }\end{array}$ & $\begin{array}{l}\text { Gana } 6.7 \text { años de esperanza } \\
\text { de vida }\end{array}$ & & $\begin{array}{l}\text { Gana } 3.9 \text { años de esperan- } \\
\text { za de vida }\end{array}$ & \\
\hline \multirow{9}{*}{$\frac{\text { 을 }}{\frac{0}{0}}$} & & Atrae $16.4 \%$ de costarricenses & & & $\begin{array}{l}\text { Atrae } 16.9 \% \text { de hon- } \\
\text { dureños }\end{array}$ & $\begin{array}{l}\text { Atrae } 38.8 \% \text { de nicara- } \\
\text { güenses }\end{array}$ & $\begin{array}{l}\text { Atrae } 17.4 \% \text { de pa- } \\
\text { nameños }\end{array}$ \\
\hline & & Gana 5.2 pp$^{1}$ en línea de pobreza ${ }^{2}$ & & & $\begin{array}{l}\text { Gana } 43.5 \mathrm{pp}^{1} \text { en lí- } \\
\text { nea de pobreza }\end{array}$ & $\begin{array}{l}\text { Gana } 29.7 \mathrm{pp}^{1} \text { en línea de } \\
\text { pobreza2 }\end{array}$ & \\
\hline & & $\begin{array}{l}\text { Gana } 2.9 \text { pp }{ }^{1} \text { en menor concentra- } \\
\text { ción Gini ingresos }\end{array}$ & & & $\begin{array}{l}\text { Gana } 10.3 \mathrm{pp}^{1} \text { en } \\
\text { menor concentración } \\
\text { Gini ingresos }\end{array}$ & $\begin{array}{l}\text { Gana } 4.9 \mathrm{pp}^{1} \text { en menor } \\
\text { concentración Gini in- } \\
\text { gresos }\end{array}$ & $\begin{array}{l}\text { Gana } 4.9 \mathrm{pp}^{1} \text { en me- } \\
\text { nor concentración } \\
\text { Gini ingresos }\end{array}$ \\
\hline & & Gana $\$ 28,044 \mathrm{PPA}^{3}$ & & & Gana $\$ 33,709$ PPA $^{3}$ & Gana $\$ 34,603 \mathrm{PPA}^{3}$ & Gana $\$ 28,146$ PPA $^{3}$ \\
\hline & & $\begin{array}{l}2.8 \text { alumnos menos por maestro, } \\
\text { 1aria. }\end{array}$ & & & $\begin{array}{l}17.7 \text { alumnos menos } \\
\text { por maestro, Primaria }\end{array}$ & $\begin{array}{l}13.6 \text { alumnos menos por } \\
\text { maestro, Primaria }\end{array}$ & $\begin{array}{l}8 \text { alumnos menos } \\
\text { por maestro, Pri- } \\
\text { maria }\end{array}$ \\
\hline & & $\begin{array}{l}\text { Gana aprox } 30.9 \mathrm{pp}^{1} \text { de mayores } \\
\text { de } 25 \text { años con al menos secunda- } \\
\text { ria completa }\end{array}$ & & & $\begin{array}{l}\text { Gana aprox } 49.9 \mathrm{pp}^{1} \\
\text { de mayores de } 25 \\
\text { años con al menos } \\
\text { secundaria completa }\end{array}$ & $\begin{array}{l}\text { Gana aprox } 45.9 \mathrm{pp}^{1} \text { de } \\
\text { mayores de } 25 \text { años con } \\
\text { al menos secundaria com- } \\
\text { pleta }\end{array}$ & \\
\hline & & $\begin{array}{l}\text { Baja en } 3.1 \mathrm{pm}^{4} \text { la mortalidad de } \\
\text { menores de } 5 \text { años }\end{array}$ & & & $\begin{array}{l}\text { Baja en } 15.9 \text { pm4 la } \\
\text { mortalidad de meno- } \\
\text { res de } 5 \text { años }\end{array}$ & $\begin{array}{l}\text { Baja en } 11.9 \mathrm{pm}^{4} \text { la mor- } \\
\text { talidad de menores de } 5 \\
\text { años }\end{array}$ & $\begin{array}{l}\text { Baja en } 8.9 \mathrm{pm}^{4} \text { la } \\
\text { mortalidad de me- } \\
\text { nores de } 5 \text { años }\end{array}$ \\
\hline & & $\begin{array}{l}\text { Baja en } 23 p c^{5} \text { la mortalidad ma- } \\
\text { terna }\end{array}$ & & & 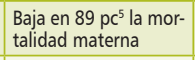 & $\begin{array}{l}\text { Baja en } 79 p c^{5} \text { la mortali- } \\
\text { dad materna }\end{array}$ & $\begin{array}{l}\text { Baja en } 50 \mathrm{pc}^{5} \text { la } \\
\text { mortalidad materna }\end{array}$ \\
\hline & & $\begin{array}{l}\text { Pierde } 1.8 \text { años de esperanza de } \\
\text { vida }\end{array}$ & & & $\begin{array}{l}\text { Gana } 4.4 \text { años de es- } \\
\text { peranza de vida }\end{array}$ & $\begin{array}{l}\text { Gana } 3.5 \text { años de esperan- } \\
\text { za de vida }\end{array}$ & $\begin{array}{l}\text { Gana } 1.4 \text { años de es- } \\
\text { peranza de vida }\end{array}$ \\
\hline \multirow{9}{*}{ 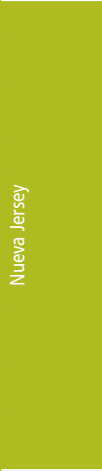 } & & Atrae $15.8 \%$ de costarricenses & & & & & \\
\hline & & $\begin{array}{l}\text { Gana } 11.4 \mathrm{pp}^{1} \text { en línea de po- } \\
\text { breza }^{2}\end{array}$ & & & & & \\
\hline & & $\begin{array}{l}\text { Gana } 3.9 \text { pp en menor concentra- } \\
\text { ción Gini ingresos }\end{array}$ & & & & & \\
\hline & & Gana $\$ 42,154 \mathrm{PPA}^{3}$ & & & & & \\
\hline & & $\begin{array}{l}6.4 \text { alumnos menos por maestro, } \\
\text { 1aria. }\end{array}$ & & & & & \\
\hline & & $\begin{array}{l}\text { Gana aprox } 31.7 \mathrm{pp}^{1} \text { de mayores } \\
\text { de } 25 \text { años con al menos secunda- } \\
\text { ria completa }\end{array}$ & & & & & \\
\hline & & $\begin{array}{l}\text { Baja en } 5.8 \mathrm{pm}^{4} \text { la mortalidad de } \\
\text { menores de } 5 \text { años }\end{array}$ & & & & & \\
\hline & & $\begin{array}{l}\text { Baja en } 20 p c^{5} \text { la mortalidad ma- } \\
\text { terna }\end{array}$ & & & & & \\
\hline & & $\begin{array}{l}\text { Pierde } 1.8 \text { años de esperanza de } \\
\text { vida }\end{array}$ & & & & & \\
\hline \multirow{7}{*}{$\begin{array}{l}\frac{1}{2} \\
\frac{2}{0} \\
\frac{0}{2} \\
\frac{0}{2}\end{array}$} & & & & & & & $\begin{array}{l}\text { Atrae } 17 \% \text { de pana- } \\
\text { meños }\end{array}$ \\
\hline & & & & & & & $\begin{array}{l}\text { Gana } 2.4 \mathrm{pp}^{1} \text { en me- } \\
\text { nor concentración } \\
\text { Gini ingresos }\end{array}$ \\
\hline & & & & & & & Gana $\$ 45,749$ PPA $^{3}$ \\
\hline & & & & & & & $\begin{array}{l}11.6 \text { alumnos me- } \\
\text { nos por maestro, } \\
\text { Primaria }\end{array}$ \\
\hline & & & & & & & $\begin{array}{l}\text { Baja en } 17.2 \mathrm{pm}^{4} \text { la } \\
\text { mortalidad de me- } \\
\text { nores de } 5 \text { años }\end{array}$ \\
\hline & & & & & & & $\begin{array}{l}\text { Baja en } 43 \mathrm{pc}^{5} \text { la } \\
\text { mortalidad materna }\end{array}$ \\
\hline & & & & & & & $\begin{array}{l}\text { Gana } 1.6 \text { años de es- } \\
\text { peranza de vida }\end{array}$ \\
\hline
\end{tabular}

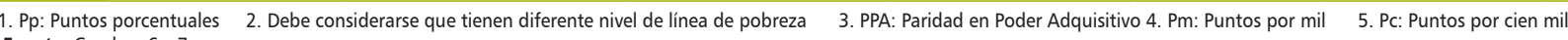
Fuente: Cuadros 6 y 7. 


\section{Cuadro F \\ Cambios en Indicadores de Migrantes Centroamericanos, por País de Origen y Estado de Destino con Concentración Media}

\begin{tabular}{|c|c|c|c|c|c|c|c|}
\hline \multirow{2}{*}{$\begin{array}{l}\text { Estado de } \\
\text { Destino }\end{array}$} & \multicolumn{7}{|c|}{ País de Origen } \\
\hline & Belice & Costa Rica & El Salvador & Guatemala & Honduras & Nicaragua & Panamá \\
\hline \multirow{9}{*}{$\frac{\frac{\sqrt{0}}{5}}{\frac{0}{\frac{0}{2}}}$} & & & & & Atrae $11.5 \%$ de hondureños & & $\begin{array}{l}\text { Atrae } 10.7 \% \text { de paname- } \\
\text { ños }\end{array}$ \\
\hline & & & & & $\begin{array}{l}\text { Gana } 44.2 \mathrm{pp}^{1} \text { en línea de po- } \\
\text { breza2 }\end{array}$ & & \\
\hline & & & & & $\begin{array}{l}\text { Gana } 10.6 \mathrm{pp}^{1} \text { en menor concen- } \\
\text { tración Gini ingresos }\end{array}$ & & $\begin{array}{l}\text { Gana } 5.2 \mathrm{pp}^{1} \text { en menor } \\
\text { concentración Gini ingre- } \\
\text { sos }\end{array}$ \\
\hline & & & & & Gana $\$ 44,343$ PPA $^{3}$ & & Gana $\$ 38,780 \mathrm{PPA}^{3}$ \\
\hline & & & & & $\begin{array}{l}12.4 \text { alumnos menos por maes- } \\
\text { tro, Primaria }\end{array}$ & & $\begin{array}{l}2.7 \text { alumnos menos por } \\
\text { maestro, Primaria }\end{array}$ \\
\hline & & & & & $\begin{array}{l}\text { Gana aprox } 46.6 \mathrm{pp}^{1} \text { de mayores } \\
\text { de } 25 \text { años con al menos secun- } \\
\text { daria completa }\end{array}$ & & \\
\hline & & & & & $\begin{array}{l}\text { Baja en } 24.7 \text { pm }^{4} \text { la mortalidad } \\
\text { de menores de } 5 \text { años }\end{array}$ & & $\begin{array}{l}\text { Baja en } 17.7 \mathrm{pm}^{4} \text { la mor- } \\
\text { talidad de menores de } 5 \\
\text { años }\end{array}$ \\
\hline & & & & & $\begin{array}{l}\text { Baja en } 97 \text { pc }^{5} \text { la mortalidad ma- } \\
\text { terna }\end{array}$ & & $\begin{array}{l}\text { Baja en } 58 p^{5} \text { la mortali- } \\
\text { dad materna }\end{array}$ \\
\hline & & & & & $\begin{array}{l}\text { Gana } 4.8 \text { años de esperanza de } \\
\text { vida }\end{array}$ & & $\begin{array}{l}\text { Gana } 1.8 \text { años de esperan- } \\
\text { za de vida }\end{array}$ \\
\hline \multirow{9}{*}{ 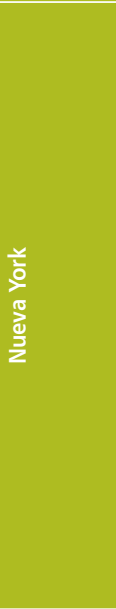 } & & & & & Atrae $11.4 \%$ de hondureños & & \\
\hline & & & & & $\begin{array}{l}\text { Gana } 45.1 \text { pp }^{1} \text { en línea de po- } \\
\text { breza }^{2}\end{array}$ & & \\
\hline & & & & & $\begin{array}{l}\text { Gana } 7.8 \mathrm{pp}^{1} \text { en menor concen- } \\
\text { tración Gini ingresos }\end{array}$ & & \\
\hline & & & & & Gana $\$ 51,312$ PPA $^{3}$ & & \\
\hline & & & & & $\begin{array}{l}21.3 \text { alumnos menos por maes- } \\
\text { tro, Primaria }\end{array}$ & & \\
\hline & & & & & $\begin{array}{l}\text { Gana aprox } 50.3 \mathrm{pp}^{1} \text { de mayores } \\
\text { de } 25 \text { años con al menos secun- } \\
\text { daria completa }\end{array}$ & & \\
\hline & & & & & $\begin{array}{l}\text { Baja en } 24.2 \mathrm{pm}^{4} \text { la mortalidad } \\
\text { de menores de } 5 \text { años }\end{array}$ & & \\
\hline & & & & & $\begin{array}{l}\text { Baja en } 82 \text { pc }^{5} \text { la mortalidad ma- } \\
\text { terna }\end{array}$ & & \\
\hline & & & & & $\begin{array}{l}\text { Gana } 4.6 \text { años de esperanza de } \\
\text { vida }\end{array}$ & & \\
\hline \multirow{9}{*}{ 䒿 } & & & Atrae $13.5 \%$ de salvadoreños & & Atrae $14 \%$ de hondureños & & \\
\hline & & & $\begin{array}{l}\text { Gana } 37.8 \text { pp}^{1} \text { en línea de po- } \\
\text { breza }^{2}\end{array}$ & & $\begin{array}{l}\text { Gana } 42.1 \mathrm{pp}^{1} \text { en línea de po- } \\
\text { breza }^{2}\end{array}$ & & \\
\hline & & & $\begin{array}{l}\text { Tiene similar concentración Gini } \\
\text { ingresos }\end{array}$ & & $\begin{array}{l}\text { Gana } 10.8 \mathrm{pp}^{1} \text { en menor concen- } \\
\text { tración Gini ingresos }\end{array}$ & & \\
\hline & & & Gana $\$ 40,373$ PPA $^{3}$ & & Gana $\$ 41,773$ PPA $^{3}$ & & \\
\hline & & & $\begin{array}{l}18.2 \text { alumnos menos por maes- } \\
\text { tro, Primaria }\end{array}$ & & $\begin{array}{l}18.9 \text { alumnos menos por maes- } \\
\text { tro, Primaria }\end{array}$ & & \\
\hline & & & $\begin{array}{l}\text { Gana aprox } 35.9 \mathrm{pp}^{1} \text { de mayo- } \\
\text { res de } 25 \text { años con al menos } \\
\text { secundaria completa }\end{array}$ & & $\begin{array}{l}\text { Gana aprox } 45.9 \mathrm{pp}^{1} \text { de mayores } \\
\text { de } 25 \text { años con al menos secun- } \\
\text { daria completa }\end{array}$ & & \\
\hline & & & $\begin{array}{l}\text { Baja en } 10.4 \text { pm }^{4} \text { la mortalidad } \\
\text { de menores de } 5 \text { años }\end{array}$ & & $\begin{array}{l}\text { Baja en } 23.4 \text { pm }^{4} \text { la mortalidad } \\
\text { de menores de } 5 \text { años }\end{array}$ & & \\
\hline & & & $\begin{array}{l}\text { Baja en } 102 p^{5} \text { la mortalidad } \\
\text { materna }\end{array}$ & & $\begin{array}{l}\text { Baja en } 102 \mathrm{pc}^{5} \text { la mortalidad } \\
\text { materna }\end{array}$ & & \\
\hline & & & $\begin{array}{l}\text { Gana } 4.5 \text { años de esperanza de } \\
\text { vida }\end{array}$ & & $\begin{array}{l}\text { Gana } 3.6 \text { años de esperanza de } \\
\text { vida }\end{array}$ & & \\
\hline
\end{tabular}

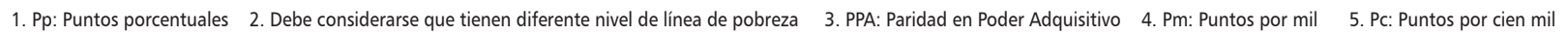

Fuente: Cuadros 6 y 7 


\section{Cuadro G (1 de 3)}

\section{Cambios en Indicadores de Migrantes Centroamericanos, por País de Origen y Estado de Destino con Concentración Baja}

\begin{tabular}{|c|c|c|c|c|c|c|c|}
\hline \multirow{2}{*}{$\begin{array}{l}\text { Estado de } \\
\text { Destino }\end{array}$} & \multicolumn{7}{|c|}{ País de Origen } \\
\hline & Belice & Costa Rica & El Salvador & Guatemala & Honduras & Nicaragua & Panamá \\
\hline \multirow{9}{*}{ 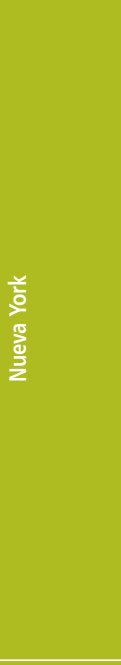 } & Atrae $9.3 \%$ de beliceños & $\begin{array}{l}\text { Atrae } 9.2 \% \text { de costarri- } \\
\text { censes }\end{array}$ & Atrae $9.2 \%$ de salvadoreños & $\begin{array}{l}\text { Atrae } 7.1 \% \text { de guatemal- } \\
\text { tecos }\end{array}$ & & & \\
\hline & $\begin{array}{l}\text { Gana } 18.5 \text { pp}^{1} \text { en línea de } \\
\text { pobreza }^{2}\end{array}$ & $\begin{array}{l}\text { Gana } 6.8 p^{1} \text { en línea de } \\
\text { pobreza }^{2}\end{array}$ & $\begin{array}{l}\text { Gana } 22.9 \mathrm{pp}^{1} \text { en línea de } \\
\text { pobreza2 }\end{array}$ & $\begin{array}{l}\text { Gana } 36.1 \mathrm{pp}^{1} \text { en línea } \\
\text { de pobreza }\end{array}$ & & & \\
\hline & & $\begin{array}{l}\text { Gana } 0.4 \mathrm{pp}^{1} \text { en menor } \\
\text { concentración Gini ingre- } \\
\text { sos }\end{array}$ & $\begin{array}{l}\text { Pierde } 3 \text { pp1 en menor con- } \\
\text { centración Gini ingresos }\end{array}$ & $\begin{array}{l}\text { Gana } 3.8 \mathrm{pp}^{1} \text { en menor } \\
\text { concentración Gini in- } \\
\text { gresos }\end{array}$ & & & \\
\hline & Gana $\$ 49,274 \mathrm{PPA}^{3}$ & Gana $\$ 45,647 \mathrm{PPA}^{3}$ & Gana $\$ 49,912 \mathrm{PPA}^{3}$ & Gana $\$ 50,476 \mathrm{PPA}^{3}$ & & & \\
\hline & $\begin{array}{l}10.6 \text { alumnos menos por } \\
\text { maestro, Primaria }\end{array}$ & $\begin{array}{l}6.4 \text { alumnos menos por } \\
\text { maestro, Primaria }\end{array}$ & $\begin{array}{l}20.6 \text { alumnos menos por } \\
\text { maestro, Primaria }\end{array}$ & $\begin{array}{l}17.4 \text { alumnos menos por } \\
\text { maestro, Primaria }\end{array}$ & & & \\
\hline & $\begin{array}{l}\text { Gana aprox } 50.3 \mathrm{pp}^{1} \text { de } \\
\text { mayores de } 25 \text { años con } \\
\text { al menos secundaria com- } \\
\text { pleta }\end{array}$ & $\begin{array}{l}\text { Gana aprox } 30.8 \mathrm{pp}^{1} \text { de } \\
\text { mayores de } 25 \text { años con } \\
\text { al menos secundaria com- } \\
\text { pleta }\end{array}$ & $\begin{array}{l}\text { Gana aprox } 40.3 \mathrm{pp}^{1} \text { de ma- } \\
\text { yores de } 25 \text { años con al me- } \\
\text { nos secundaria completa }\end{array}$ & $\begin{array}{l}\text { Gana aprox } 65.3 \mathrm{pp}^{1} \text { de } \\
\text { mayores de } 25 \text { años con } \\
\text { al menos secundaria } \\
\text { completa }\end{array}$ & & & \\
\hline & $\begin{array}{l}\text { Baja en } 12.2 \text { pm }^{4} \text { la morta- } \\
\text { lidad de menores de } 5 \text { años }\end{array}$ & $\begin{array}{l}\text { Baja en } 5.2 \text { pm }^{4} \text { la mortali- } \\
\text { dad de menores de } 5 \text { años }\end{array}$ & $\begin{array}{l}\text { Baja en } 11.2 \mathrm{pm}^{4} \text { la morta- } \\
\text { lidad de menores de } 5 \text { años }\end{array}$ & $\begin{array}{l}\text { Baja en } 34.2 \text { pm }^{4} \text { la mor- } \\
\text { talidad de menores de } 5 \\
\text { años }\end{array}$ & & & \\
\hline & $\begin{array}{l}\text { Baja en } 66 p c^{5} \text { la mortali- } \\
\text { dad materna }\end{array}$ & $\begin{array}{l}\text { Baja en } 16 p c^{5} \text { la mortali- } \\
\text { dad materna }\end{array}$ & $\begin{array}{l}\text { Baja en } 82 \mathrm{pc}^{5} \text { la mortalidad } \\
\text { materna }\end{array}$ & $\begin{array}{l}\text { Baja en } 82 \text { pc }^{5} \text { la mortali- } \\
\text { dad materna }\end{array}$ & & & \\
\hline & $\begin{array}{l}\text { Pierde } 1.6 \text { años de esperan- } \\
\text { za de vida }\end{array}$ & $\begin{array}{l}\text { Gana } 1.6 \text { años de esperan- } \\
\text { za de vida }\end{array}$ & $\begin{array}{l}\text { Gana } 5.5 \text { años de esperanza } \\
\text { de vida }\end{array}$ & $\begin{array}{l}\text { Gana } 6.5 \text { años de espe- } \\
\text { ranza de vida }\end{array}$ & & & \\
\hline \multirow{9}{*}{ 惢 } & Atrae $8.4 \%$ de beliceños & $\begin{array}{l}\text { Atrae } 5.5 \% \text { de costarri- } \\
\text { censes }\end{array}$ & & $\begin{array}{l}\text { Atrae } 6.3 \% \text { de guatemal- } \\
\text { tecos }\end{array}$ & & $\begin{array}{l}\text { Atrae } 5.7 \% \text { de nica- } \\
\text { ragüenses }\end{array}$ & $\begin{array}{l}\text { Atrae } 8.5 \% \text { de pana- } \\
\text { meños }\end{array}$ \\
\hline & $\begin{array}{l}\text { Gana } 15.6 \text { pp }{ }^{1} \text { en línea de } \\
\text { pobreza2 }\end{array}$ & $\begin{array}{l}\text { Gana } 3.8 \mathrm{pp}^{1} \text { en línea de } \\
\text { pobreza }^{2}\end{array}$ & & $\begin{array}{l}\text { Gana } 33.1 \mathrm{pp}^{1} \text { en línea } \\
\text { de pobreza }\end{array}$ & & $\begin{array}{l}\text { Gana } 28.3 \mathrm{pp}^{1} \text { en lí- } \\
\text { nea de pobreza }\end{array}$ & \\
\hline & & $\begin{array}{l}\text { Pierde } 3.3 \mathrm{pp}^{1} \text { en mayor } \\
\text { concentración Gini ingre- } \\
\text { sos }\end{array}$ & & $\begin{array}{l}\text { Gana } 6.7 \mathrm{pp}^{1} \text { en menor } \\
\text { concentración Gini in- } \\
\text { gresos }\end{array}$ & & $\begin{array}{l}\text { Gana } 5.3 \mathrm{pp}^{1} \text { en me- } \\
\text { nor concentración } \\
\text { Gini ingresos }\end{array}$ & $\begin{array}{l}\text { Gana } 5.3 \mathrm{pp}^{1} \text { en me- } \\
\text { nor concentración } \\
\text { Gini ingresos }\end{array}$ \\
\hline & Gana $\$ 39,745$ PPA $^{3}$ & Gana $\$ 36,108$ PPA $^{3}$ & & Gana $\$ 40,937 \mathrm{PPA}^{3}$ & & Gana $\$ 42,667$ PPA3 & Gana $\$ 36,210 \mathrm{PPA}^{3}$ \\
\hline & $\begin{array}{l}8.2 \text { alumnos menos por } \\
\text { maestro, Primaria }\end{array}$ & $\begin{array}{l}4 \text { alumnos menos por } \\
\text { maestro, Primaria }\end{array}$ & & $\begin{array}{l}15 \text { alumnos menos por } \\
\text { maestro, Primaria }\end{array}$ & & $\begin{array}{l}14.8 \text { alumnos me- } \\
\text { nos por maestro, } \\
\text { Primaria }\end{array}$ & $\begin{array}{l}9.2 \text { alumnos menos } \\
\text { por maestro, Pri- } \\
\text { maria }\end{array}$ \\
\hline & $\begin{array}{l}\text { Gana aprox } 45.9 \mathrm{pp}^{1} \text { de } \\
\text { mayores de } 25 \text { años con } \\
\text { al menos secundaria com- } \\
\text { pleta }\end{array}$ & $\begin{array}{l}\text { Gana aprox } 26.4 \mathrm{pp}^{1} \text { de } \\
\text { mayores de } 25 \text { años con } \\
\text { al menos secundaria com- } \\
\text { pleta }\end{array}$ & & $\begin{array}{l}\text { Gana aprox } 60.9 \mathrm{pp}^{1} \text { de } \\
\text { mayores de } 25 \text { años con } \\
\text { al menos secundaria } \\
\text { completa }\end{array}$ & & $\begin{array}{l}\text { Gana aprox } 41.9 \mathrm{pp}^{1} \\
\text { de mayores de } 25 \\
\text { años con al menos } \\
\text { secundaria completa }\end{array}$ & \\
\hline & $\begin{array}{l}\text { Baja en } 11.4 \text { pm }^{4} \text { la morta- } \\
\text { lidad de menores de } 5 \text { años }\end{array}$ & $\begin{array}{l}\text { Baja en } 4.4 \text { pm4 la mortali- } \\
\text { dad de menores de } 5 \text { años }\end{array}$ & & $\begin{array}{l}\text { Baja en } 33.4 \text { pm }^{4} \text { la mor- } \\
\text { talidad de menores de } 5 \\
\text { años }\end{array}$ & & $\begin{array}{l}\text { Baja en } 19.4 \mathrm{pm}^{4} \text { la } \\
\text { mortalidad de me- } \\
\text { nores de } 5 \text { años }\end{array}$ & $\begin{array}{l}\text { Baja en } 16.4 \mathrm{pm}^{4} \text { la } \\
\text { mortalidad de meno- } \\
\text { res de } 5 \text { años }\end{array}$ \\
\hline & $\begin{array}{l}\text { Baja en } 86 p c^{5} \text { la mortali- } \\
\text { dad materna }\end{array}$ & $\begin{array}{l}\text { Baja en } 36 p c^{5} \text { la mortali- } \\
\text { dad materna }\end{array}$ & & $\begin{array}{l}\text { Baja en } 102 \text { pc }^{5} \text { la morta- } \\
\text { lidad materna }\end{array}$ & & $\begin{array}{l}\text { Baja en } 92 \mathrm{pc}^{5} \text { la } \\
\text { mortalidad materna }\end{array}$ & $\begin{array}{l}\text { Baja en } 63 \mathrm{pc}^{5} \text { la mor- } \\
\text { talidad materna }\end{array}$ \\
\hline & $\begin{array}{l}\text { Gana } 0.6 \text { años de esperan- } \\
\text { za de vida }\end{array}$ & $\begin{array}{l}\text { Pierde } 2.6 \text { años de espe- } \\
\text { ranza de vida }\end{array}$ & & $\begin{array}{l}\text { Gana } 5.5 \text { años de espe- } \\
\text { ranza de vida }\end{array}$ & & $\begin{array}{l}\text { Gana } 2.7 \text { años de es- } \\
\text { peranza de vida }\end{array}$ & $\begin{array}{l}\text { Gana } 0.6 \text { años de es- } \\
\text { peranza de vida }\end{array}$ \\
\hline \multirow{9}{*}{$\frac{\frac{\pi}{2}}{\frac{0}{2}}$} & Atrae $5.4 \%$ de beliceños & & & $\begin{array}{l}\text { Atrae } 8 \% \text { de guatemal- } \\
\text { tecos }\end{array}$ & & & \\
\hline & $\begin{array}{l}\text { Gana } 17 \mathrm{pp}^{1} \text { en línea de } \\
\text { pobreza2 }\end{array}$ & & & $\begin{array}{l}\text { Gana } 34.5 \mathrm{pp}^{1} \text { en línea } \\
\text { de pobreza }^{2}\end{array}$ & & & \\
\hline & & & & $\begin{array}{l}\text { Gana } 6.3 \mathrm{pp}^{1} \text { en menor } \\
\text { concentración Gini in- } \\
\text { gresos }\end{array}$ & & & \\
\hline & Gana $\$ 31,671 \mathrm{PPA}^{3}$ & & & Gana $\$ 32,873 \mathrm{PPA}^{3}$ & & & \\
\hline & $\begin{array}{l}7 \text { alumnos menos por } \\
\text { maestro, Primaria }\end{array}$ & & & $\begin{array}{l}13.8 \text { alumnos menos por } \\
\text { maestro, Primaria }\end{array}$ & & & \\
\hline & $\begin{array}{l}\text { Gana aprox } 49.9 \mathrm{pp}^{1} \text { de } \\
\text { mayores de } 25 \text { años con } \\
\text { al menos secundaria com- } \\
\text { pleta }\end{array}$ & & & $\begin{array}{l}\text { Gana aprox } 64.9 \mathrm{pp}^{1} \text { de } \\
\text { mayores de } 25 \text { años con } \\
\text { al menos secundaria } \\
\text { completa }\end{array}$ & & & \\
\hline & $\begin{array}{l}\text { Baja en } 3.9 \text { pm }^{4} \text { la mortali- } \\
\text { dad de menores de } 5 \text { años }\end{array}$ & & & $\begin{array}{l}\text { Baja en } 25.9 \text { pm }^{4} \text { la mor- } \\
\text { talidad de menores de } 5 \\
\text { años }\end{array}$ & & & \\
\hline & $\begin{array}{l}\text { Baja en } 73 p c^{5} \text { la mortali- } \\
\text { dad materna }\end{array}$ & & & $\begin{array}{l}\text { Baja en } 89 \mathrm{pc}^{5} \text { la mortali- } \\
\text { dad materna }\end{array}$ & & & \\
\hline & $\begin{array}{l}\text { Gana } 1.4 \text { años de esperan- } \\
\text { za de vida }\end{array}$ & & & $\begin{array}{l}\text { Gana } 6.3 \text { años de espe- } \\
\text { ranza de vida }\end{array}$ & & & \\
\hline
\end{tabular}

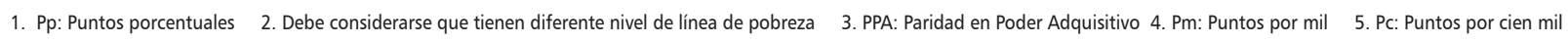




\section{Cuadro $\mathrm{G}(2$ de 3 )}

\section{Cambios en Indicadores de Migrantes Centroamericanos, por País de Origen y Estado de Destino con Concentración Baja}

\begin{tabular}{|c|c|c|c|c|c|c|c|}
\hline \multirow{2}{*}{$\begin{array}{l}\text { Estado de } \\
\text { Destino }\end{array}$} & \multicolumn{7}{|c|}{ País de Origen } \\
\hline & Belice & Costa Rica & El Salvador & Guatemala & Honduras & Nicaragua & Panamá \\
\hline \multirow{9}{*}{$\frac{\text { 营 }}{\frac{5}{5}}$} & Atrae $4.5 \%$ de beliceños & & Atrae $7.5 \%$ de salvadoreños & & $\begin{array}{l}\text { Atrae } 4.8 \% \text { de hondu- } \\
\text { reños }\end{array}$ & & $\begin{array}{l}\text { Atrae } 4.3 \% \text { de pa- } \\
\text { nameños }\end{array}$ \\
\hline & $\begin{array}{l}\text { Gana } 22.4 \mathrm{pp}^{1} \text { en línea de } \\
\text { pobreza2 }\end{array}$ & & $\begin{array}{l}\text { Gana } 26.7 p^{1} \text { en línea de po- } \\
\text { breza2 }\end{array}$ & & $\begin{array}{l}\text { Gana } 48.9 \mathrm{pp}^{1} \text { en línea de } \\
\text { pobreza2 }\end{array}$ & & \\
\hline & & & $\begin{array}{l}\text { Gana } 1.0 \mathrm{pp}^{1} \text { en menor con- } \\
\text { centración Gini ingresos }\end{array}$ & & $\begin{array}{l}\text { Gana } 11.8 \mathrm{pp}^{1} \text { en menor } \\
\text { concentración Gini in- } \\
\text { gresos }\end{array}$ & & $\begin{array}{l}\text { Gana } 6.4 \mathrm{pp}^{1} \text { en me- } \\
\text { nor concentración } \\
\text { Gini ingresos }\end{array}$ \\
\hline & Gana $\$ 43,366$ PPA $^{3}$ & & Gana $\$ 44,004$ PPA $^{3}$ & & Gana $\$ 45,454 \mathrm{PPA}^{3}$ & & Gana $\$ 39,841$ PPA3 \\
\hline & $\begin{array}{l}10.9 \text { alumnos menos por } \\
\text { maestro, Primaria }\end{array}$ & & $\begin{array}{l}20.9 \text { alumnos menos por } \\
\text { maestro, Primaria }\end{array}$ & & $\begin{array}{l}21.6 \text { alumnos menos por } \\
\text { maestro, Primaria }\end{array}$ & & $\begin{array}{l}11.9 \text { alumnos me- } \\
\text { nos por maestro, } \\
\text { Primaria }\end{array}$ \\
\hline & $\begin{array}{l}\text { Gana aprox } 52.6 \mathrm{pp}^{1} \text { de } \\
\text { mayores de } 25 \text { años con al } \\
\text { menos secundaria completa }\end{array}$ & & $\begin{array}{l}\text { Gana aprox } 42.6 \mathrm{pp}^{1} \text { de mayo- } \\
\text { res de } 25 \text { años con al menos } \\
\text { secundaria completa }\end{array}$ & & $\begin{array}{l}\text { Gana aprox } 52.6 \mathrm{pp}^{1} \\
\text { de mayores de } 25 \text { años } \\
\text { con al menos secundaria } \\
\text { completa }\end{array}$ & & \\
\hline & $\begin{array}{l}\text { Baja en } 10.5 \text { pm }^{4} \text { la morta- } \\
\text { lidad de menores de } 5 \text { años }\end{array}$ & & $\begin{array}{l}\text { Baja en } 9.5 \text { pm }^{4} \text { la mortalidad } \\
\text { de menores de } 5 \text { años }\end{array}$ & & $\begin{array}{l}\text { Baja en } 22.5 \text { pm }^{4} \text { la mor- } \\
\text { talidad de menores de } 5 \\
\text { años }\end{array}$ & & $\begin{array}{l}\text { Baja en } 15.5 \mathrm{pm}^{4} \text { la } \\
\text { mortalidad de me- } \\
\text { nores de } 5 \text { años }\end{array}$ \\
\hline & $\begin{array}{l}\text { Baja en } 78 \mathrm{pc}^{5} \text { la mortalidad } \\
\text { materna }\end{array}$ & & $\begin{array}{l}\text { Baja en } 94 \mathrm{pc}^{5} \text { la mortalidad } \\
\text { materna }\end{array}$ & & $\begin{array}{l}\text { Baja en } 94 p c^{5} \text { la mortali- } \\
\text { dad materna }\end{array}$ & & $\begin{array}{l}\text { Baja en } 55 \mathrm{pc}^{5} \text { la } \\
\text { mortalidad materna }\end{array}$ \\
\hline & $\begin{array}{l}\text { Gana } 0.7 \text { años de esperanza } \\
\text { de vida }\end{array}$ & & $\begin{array}{l}\text { Gana } 4.6 \text { años de esperanza } \\
\text { de vida }\end{array}$ & & $\begin{array}{l}\text { Gana } 3.7 \text { años de espe- } \\
\text { ranza de vida }\end{array}$ & & $\begin{array}{l}\text { Gana } 0.7 \text { años de } \\
\text { esperanza de vida }\end{array}$ \\
\hline \multirow{9}{*}{$\frac{\substack{\frac{0}{5} \\
\frac{10}{10}}}{\sum^{\frac{10}{10}}}$} & & & Atrae $7.5 \%$ de salvadoreños & & & & \\
\hline & & & $\begin{array}{l}\text { Gana } 27.9 \text { pp en línea de po- } \\
\text { breza2 }\end{array}$ & & & & \\
\hline & & & $\begin{array}{l}\text { Gana } 2.6 \mathrm{pp}^{1} \text { en menor con- } \\
\text { centración Gini ingresos }\end{array}$ & & & & \\
\hline & & & Gana $\$ 42,354 \mathrm{PPA}^{3}$ & & & & \\
\hline & & & $\begin{array}{l}18.5 \text { alumnos menos por } \\
\text { maestro, Primaria }\end{array}$ & & & & \\
\hline & & & $\begin{array}{l}\text { Gana aprox } 42.4 \mathrm{pp}^{1} \text { de mayo- } \\
\text { res de } 25 \text { años con al menos } \\
\text { secundaria completa }\end{array}$ & & & & \\
\hline & & & $\begin{array}{l}\text { Baja en } 9.7 \text { pm }^{4} \text { la mortalidad } \\
\text { de menores de } 5 \text { años }\end{array}$ & & & & \\
\hline & & & $\begin{array}{l}\text { Baja en } 93 p c^{5} \text { la mortalidad } \\
\text { materna }\end{array}$ & & & & \\
\hline & & & $\begin{array}{l}\text { Gana } 4.1 \text { años de esperanza } \\
\text { de vida }\end{array}$ & & & & \\
\hline \multirow{9}{*}{ 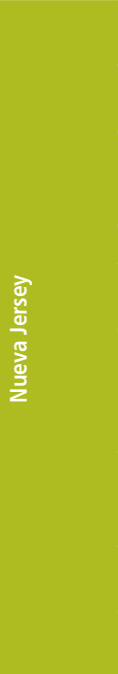 } & & & & $\begin{array}{l}\text { Atrae } 4.7 \% \text { de guatemal- } \\
\text { tecos }\end{array}$ & $\begin{array}{l}\text { Atrae } 5.8 \% \text { de hondu- } \\
\text { reños }\end{array}$ & & \\
\hline & & & & $\begin{array}{l}\text { Gana } 40.7 p^{1} \text { en línea de } \\
\text { pobreza2 }\end{array}$ & $\begin{array}{l}\text { Gana } 49.7 \text { pp }^{1} \text { en línea de } \\
\text { pobreza }^{2}\end{array}$ & & \\
\hline & & & & $\begin{array}{l}\text { Gana } 7.3 \mathrm{pp}^{1} \text { en menor } \\
\text { concentración Gini ingre- } \\
\text { sos }\end{array}$ & $\begin{array}{l}\text { Gana } 11.3 \mathrm{pp}^{1} \text { en menor } \\
\text { concentración Gini in- } \\
\text { gresos }\end{array}$ & & \\
\hline & & & & Gana $\$ 46,983 \mathrm{PPA}^{3}$ & Gana $\$ 47,819$ PPA $^{3}$ & & \\
\hline & & & & $\begin{array}{l}17.4 \text { alumnos menos por } \\
\text { maestro, Primaria }\end{array}$ & $\begin{array}{l}21.3 \text { alumnos menos por } \\
\text { maestro, Primaria }\end{array}$ & & \\
\hline & & & & $\begin{array}{l}\text { Gana aprox } 65.7 \mathrm{pp}^{1} \text { de } \\
\text { mayores de } 25 \text { años con } \\
\text { al menos secundaria com- } \\
\text { pleta }\end{array}$ & $\begin{array}{l}\text { Gana aprox } 50.7 \mathrm{pp}^{1} \\
\text { de mayores de } 25 \text { años } \\
\text { con al menos secundaria } \\
\text { completa }\end{array}$ & & \\
\hline & & & & $\begin{array}{l}\text { Baja en } 34.8 \mathrm{pm}^{4} \text { la mor- } \\
\text { talidad de menores de } 5 \\
\text { años }\end{array}$ & $\begin{array}{l}\text { Baja en } 24.8 \text { pm }^{4} \text { la mor- } \\
\text { talidad de menores de } 5 \\
\text { años }\end{array}$ & & \\
\hline & & & & $\begin{array}{l}\text { Baja en } 86 p c^{5} \text { la mortali- } \\
\text { dad materna }\end{array}$ & $\begin{array}{l}\text { Baja en } 86 p c^{5} \text { la mortali- } \\
\text { dad materna }\end{array}$ & & \\
\hline & & & & $\begin{array}{l}\text { Gana } 6.3 \text { años de esperan- } \\
\text { za de vida }\end{array}$ & $\begin{array}{l}\text { Gana } 4.4 \text { años de espe- } \\
\text { ranza de vida }\end{array}$ & & \\
\hline
\end{tabular}




\section{Cuadro $\mathrm{G}$ (3 de 3)}

\section{Cambios en Indicadores de Migrantes Centroamericanos, por País de Origen y Estado de Destino con Concentración Baja}

\begin{tabular}{|c|c|c|c|c|c|c|c|}
\hline \multirow{2}{*}{$\begin{array}{l}\text { Estado de } \\
\text { Destino }\end{array}$} & \multicolumn{7}{|c|}{ País de Origen } \\
\hline & Belice & Costa Rica & El Salvador & Guatemala & Honduras & Nicaragua & Panamá \\
\hline \multirow{9}{*}{ 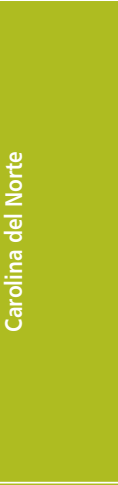 } & & & & & Atrae $4.9 \%$ de hondureños & & \\
\hline & & & & & Gana 42.5 pp$^{1}$ en línea de pobreza ${ }^{2}$ & & \\
\hline & & & & & $\begin{array}{l}\text { Gana } 11.3 \mathrm{pp}^{1} \text { en menor concentración } \\
\text { Gini ingresos }\end{array}$ & & \\
\hline & & & & & Gana $\$ 37,782$ PPA $^{3}$ & & \\
\hline & & & & & $\begin{array}{l}18.9 \text { alumnos menos por maestro, Pri- } \\
\text { maria }\end{array}$ & & \\
\hline & & & & & $\begin{array}{l}\text { Gana aprox } 51.3 \mathrm{pp}^{1} \text { de mayores de } 25 \\
\text { años con al menos secundaria completa }\end{array}$ & & \\
\hline & & & & & $\begin{array}{l}\text { Baja en } 21.2 \text { pm }^{4} \text { la mortalidad de meno- } \\
\text { res de } 5 \text { años }\end{array}$ & & \\
\hline & & & & & Baja en $87 p c^{5}$ la mortalidad materna & & \\
\hline & & & & & Gana 2.7 años de esperanza de vida & & \\
\hline \multirow{9}{*}{ 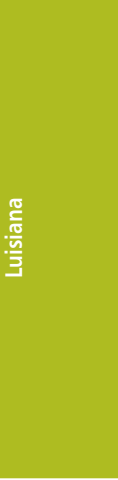 } & & & & & Atrae $4.8 \%$ de hondureños & & \\
\hline & & & & & Gana 41.3 pp en línea de pobreza ${ }^{2}$ & & \\
\hline & & & & & $\begin{array}{l}\text { Gana } 10.1 \mathrm{pp}^{1} \text { en menor concentración } \\
\text { Gini ingresos }\end{array}$ & & \\
\hline & & & & & Gana $\$ 40,923$ PPA $^{3}$ & & \\
\hline & & & & & $\begin{array}{l}19.3 \text { alumnos menos por maestro, Pri- } \\
\text { maria }\end{array}$ & & \\
\hline & & & & & $\begin{array}{l}\text { Gana aprox } 54.2 \mathrm{pp}^{1} \text { de mayores de } 25 \\
\text { años con al menos secundaria completa }\end{array}$ & & \\
\hline & & & & & $\begin{array}{l}\text { Baja en } 23.4 \text { pm }^{4} \text { la mortalidad de meno- } \\
\text { res de } 5 \text { años }\end{array}$ & & \\
\hline & & & & & Baja en $88 \mathrm{pc}^{5}$ la mortalidad materna & & \\
\hline & & & & & Gana 1.1 años de esperanza de vida & & \\
\hline \multirow{7}{*}{ 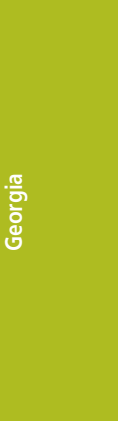 } & & & & & & & Atrae $5.2 \%$ de panameños \\
\hline & & & & & & & $\begin{array}{l}\text { Gana } 5.4 \mathrm{pp}^{1} \text { en menor concen- } \\
\text { tración Gini ingresos }\end{array}$ \\
\hline & & & & & & & Gana $\$ 29,682 \mathrm{PPA}^{3}$ \\
\hline & & & & & & & $\begin{array}{l}\text { 9.7 alumnos menos por maestro, } \\
\text { Primaria }\end{array}$ \\
\hline & & & & & & & $\begin{array}{l}\text { Baja en } 14.8 \text { pm }^{4} \text { la mortalidad } \\
\text { de menores de } 5 \text { años }\end{array}$ \\
\hline & & & & & & & $\begin{array}{l}\text { Baja en } 60 \mathrm{pc}^{5} \text { la mortalidad ma- } \\
\text { terna }\end{array}$ \\
\hline & & & & & & & $\begin{array}{l}\text { Pierde } 0.8 \text { años de esperanza de } \\
\text { vida }\end{array}$ \\
\hline
\end{tabular}

1. Pp: Puntos porcentuales

2. Debe considerarse que tienen diferente nivel de línea de pobreza

3. PPA: Paridad en Poder Adquisitivo

4. Pm: Puntos por mil

5. Pc: Puntos por cien mil

Fuente: Cuadros 6 y 7 